\title{
High-performance Sunlight Induced Polymerization Using Novel Push-pull dyes with high light absorption properties
}

\author{
Ke Sun ${ }^{1,2}$, Hong Chen ${ }^{1,2}$, Yijun Zhang ${ }^{1,2}$, Fabrice Morlet-Savary ${ }^{1,2}$, Bernadette \\ Graff $^{1,2}, \mathrm{Pu} \mathrm{Xiao}^{3 *}$, Frédéric Dumur $^{4 *}$, Jacques Lalevée ${ }^{1,2^{*}}$ \\ ${ }^{1}$ Université de Haute-Alsace, CNRS, IS2M UMR 7361, F-68100 Mulhouse, France \\ ${ }^{2}$ Université de Strasbourg, France \\ ${ }^{3}$ Research School of Chemistry, Australian National University, Canberra, ACT 2601, \\ Australia \\ ${ }^{4}$ Aix Marseille Univ, CNRS, ICR UMR 7273, F-13397 Marseille, France
}

*Corresponding author: pu.xiao@anu.edu.au (P. X.); frederic.dumur@univ-amu.fr; jacques.lalevée@uha.fr(J. L.),

\begin{abstract}
In this article, a series of three-component photoinitiating systems (PISs) based on push-pull dyes are proposed. The systems are composed of the newly synthesized push-pull dyes and different co-initiators, namely an iodonium salt and a tertiary amine (ethyl dimethylaminobenzoate EDB). Photoinitiation abilities and photochemical properties of the different investigated photoinitiating systems were studied in detail. Notably, the mechanisms related to the polymerization efficiencies were determined using different techniques such as UV-visible absorption and fluorescence spectroscopy. Moreover, the photoinitiation abilities of the threecomponent systems for the sunlight-induced polymerization processes were also
\end{abstract}


examined, indicating that sunlight can act as an effective light source for photopolymerization. Finally, 3D patterns with a spatial resolution were successfully produced by the direct laser writing (DLW) approach, even with photosensitive resins containing silica fillers.

Keywords: push-pull dye; free radical polymerization; three-component system; LED; sunlight; 3D printing.

\section{Introduction}

Push-pull dyes are mainly composed of two distinct moieties i.e. an electron donor and an electron acceptor parts connected by mean of a conjugated spacer. Push-pull dyes are highly attractive as the absorption spectra of these dyes can be finely tuned by mean of not only the length of the $\pi$-conjugated spacer but also the electron-withdrawing or electron releasing ability of the two moieties attached at both end of the spacer. Push-pull dyes are also characterized by an intense absorption band located in the visible range and this absorption band typically corresponds to the intramolecular charge transfer (ICT) band, whose position can be finely tune by chemical engineering. ${ }^{1-5}$ Benefiting from their high molar extinction coefficients and excellent photoinitiation abilities in photopolymerization, push-pull dyes based on D- $\pi$-A structures (with D and A which stands for donor and acceptor respectively) have been proposed as visible light sensitive photoinitiators since 2013. ${ }^{6-10}$ Considering that push-pull dyes can easily exhibit high molar extinction coefficients, compounds of this family were thus candidates of choice for practical applications in Organic Electronics including organic photovoltaics (OPVs), ${ }^{11,12}$ organic light-emitting diodes (OLEDs), ${ }^{13}$ organic-field effects transistors (OFETs), ${ }^{14}$ nonlinear optics (NLO) ${ }^{15-19}$ to waste-water treatment. ${ }^{20}$ However, polymerization under mild conditions is still a challenge (low light intensity, under air). Indeed, 
availability of dyes with push-pull structures that meet the demand of high reactive photoinitiators while using low light intensities are still scarce in practice. ${ }^{21}$ Face to this consideration, there is still a huge interest to develop new push-pull dyes, especially with aim at developing dyes absorbing at $405 \mathrm{~nm}$ which is the wavelength under use in $3 \mathrm{D}$ printing. Parallel to this, Sun is the cheapest light source on Earth and Sun can be advantageously used in order to initiate polymerization processes. $^{22}$

Previous studies have shown that polymerists could use sunlight to initiate photopolymerization processes because of its advantages, e.g. mild light intensity, broad emission spectrum, and cost-effective etc. ${ }^{23-26}$ Because of its characteristics e.g. free and unlimitedness, sunlight can significantly decrease the energy consumption, because sunlight not only acts as an unlimited light source on Earth, but its emission spectrum is also much broader than those of LEDs, these light sources being characterized by narrow emission spectra. ${ }^{27}$ Moreover, even if polymerization reactions can be performed at room temperature both upon LED and sunlight irradiation, sunlight is a more likely adapted light source for panchromatic photoinitiators. ${ }^{28}$ So far, effects of sunlight as a light source for photopolymerization processes such as free radical polymerization, cationic polymerization and atom transfer radical polymerization have been well discussed. ${ }^{10,21,29-31}$ Interestingly, chemical mechanisms involved in the transformation of a liquid resin into a polymeric solid were determined as being the same, namely under sunlight or upon irradiation with LEDs. According to the results reported in previous works, the use of sunlight to initiate a polymerization process not only decreases the toughness of polymerization conditions but also improves the photoinitiation performance of existing photoinitiating systems (PISs) ${ }^{32,33}$ However, activation performance of sunlight reported in previous works is not very efficient yet and photoinitiating systems based on new push-pull dyes remain less reactive than benchmark photoinitiating systems such as .... A great deal of efforts has thus to be done in order to improve the reactivity of these systems. 
The present work is focused on novel photoinitiating systems developed with six different dyes exhibiting push-pull structures (See Figure 1) which have never been used in photopolymerization. These dyes were combined with different coinitiators, namely an iodonium salt and a tertiary amine (ethyl dimethylaminobenzoate EDB). Indeed, the evaluation of their photoinitiation ability in photopolymerization is one of the main developments of this research. Real-Time Fourier Transform Infrared spectroscopy (RT-FTIR) was used as an appropriate technique to monitor the conversion of the reactive functions and the formation of the corresponding polymers. In addition, two dyes could lead to high final monomer conversions (FCs) and these two dyes were selected to examine the chemical mechanisms supporting the polymerization process. For instance, the chemical mechanisms involved in the interaction of the dyes with the two additives i.e. Iod and EDB were investigated by steady state photolysis experiments and electron spin resonance (ESR) spin-trapping techniques. Finally, a practical use of the novel dye-based PISs could be evidenced with direct laser writing (DLW) experiments, which enabled to elaborate 3D patterns with excellent spatial resolutions for both unfilled and filled samples for the access to photocomposites. 
<smiles>CC1(C)OC(=O)C(=Cc2ccc[nH]2)C(=O)O1</smiles>

1

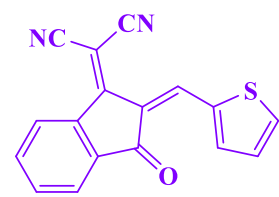

4

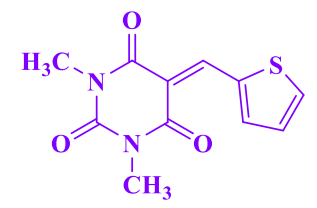

2

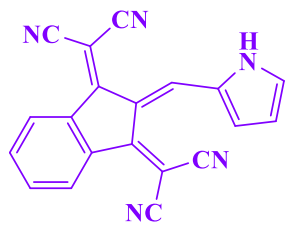

5<smiles>CN1C(=O)C(=Cc2ccc[nH]2)C(=O)N(C)C1=O</smiles>

3

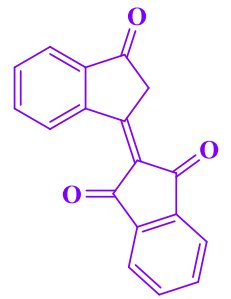

6

\section{Monomer}

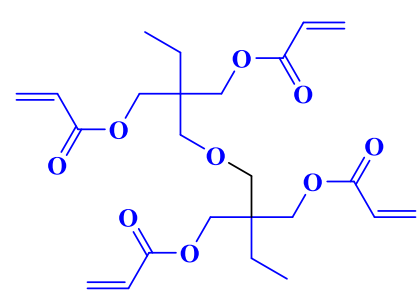

TA
Cationic photoinitiator

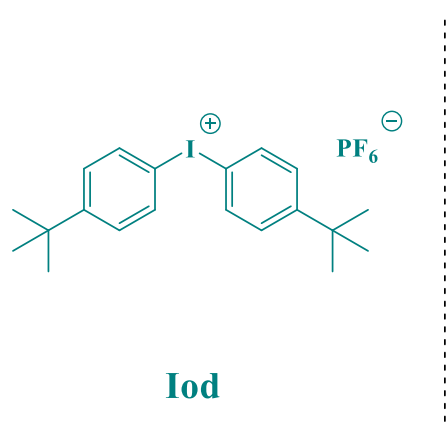

Sacrificial amine

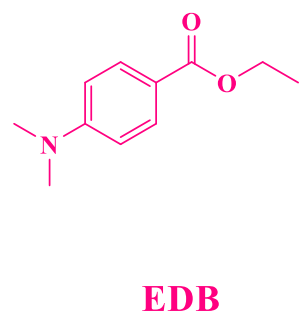

Figure 1. Chemical structures of dye 1-6, iodonium salt (Iod), the amine (EDB) and the acrylate monomer (TA) used in this study.

\section{Materials and Methods}

\subsection{Dyes}

Chemical structures of push-pull dyes 1-6 investigated in this article are presented in the Figure 1. The synthetic procedures are described below in Section 3.1 and their characterizations reported in supporting information. 


\subsection{Other Materials}

The corresponding chemical structures of a commercial iodonium salt (Iod Speedcure 938) used as co-initiators and an amine (ethyl dimethylaminobenzoate EDB) used as electron donor in this article are shown in Scheme 1. These chemicals were purchased from Lambson Ltd (UK). The benchmark acrylate monomer (TA) was purchased from Allnex and its corresponding molecular structure is also depicted in Figure 1. Green synthetic approaches towards polymers reported in this work were given in mild conditions e.g. solvent-free and mild light irradiation conditions (405 nm LED and sunlight) at room-temperature.

\subsection{Polymerization profiles obtained by Real Time Fourier Transform Infrared Spectroscopy (RT-FTIR)}

The novel dyes were dissolved with the iodonium salt (Iod) and the amine (EDB) in a benchmark monomer (tetrafunctional polyether acrylate noted TA) to build the photosensitive formulations. Their weight content ratios in monomer are: $0.1 \% / 2 \% / 2 \%$ $\mathrm{w} / \mathrm{w} / \mathrm{w}$, respectively. The prepared formulations were deposited in laminate between 2 polypropylene films. Particularly, 1 or 2 drops are enough to control the thickness at $100 \mu \mathrm{m}$, then the formulations were exposed to irradiation upon LED emitting at 405 $\mathrm{nm}\left(\mathrm{I}_{0}=110 \mathrm{~mW} \cdot \mathrm{cm}^{-2}\right)$ or sunlight to initiate the Free Radical Polymerization (FRP) at room temperature and under air. During the polymerization kinetics, the IR peak at $\sim 6130 \mathrm{~cm}^{-1}$, corresponding to a characteristic peak of the investigated acrylate monomer, was continuously monitored by real-time FTIR spectroscopy (JASCO FTIR 4100). The polymerization profiles were established using the following relationship of acrylate function conversion at a given irradiation time: $:^{34-37}$

$$
\text { conversion }(\%)=\left(A_{0}-A_{t}\right) / A_{0} \times 100
$$


where $A_{0}$ is the initial peak area before irradiation and $A_{t}$ is the peak area after irradiation for a given time $\mathrm{t}$.

\subsection{The chemical mechanisms studies}

To investigate the chemical mechanisms induced by the three-component PISs during photopolymerization, several techniques, e.g. photolysis experiments and fluorescence approaches were performed by UV-visible absorption spectroscopy (JASCO V730 UV-visible spectrometer) and fluorescence spectroscopy (JASCO FP6200 spectrofluorimeter), respectively. The singlet excited state energy level (Es 1 ) was calculated from the crossing point of the UV-visible and fluorescence spectra. The Stern-Volmer coefficients (Ksv) were determined by the slopes of Stern-Volmer treatment for fluorescence quenching and the electron transfer quantum yields $\left(\phi_{\mathrm{et}}\right)$ were calculated using the eq. $2: 35,36$

$$
\phi_{\mathrm{et}}=\mathrm{K}_{\mathrm{sv}}[\text { additive }] /\left(1+\mathrm{K}_{\mathrm{sv}}[\text { additive }]\right)
$$

Cyclic voltammetry enabled to determine the redox potentials of the selected dyes (oxidation potential noted $\mathrm{E}_{\mathrm{ox}}$ and reduction potential noted $\mathrm{E}_{\mathrm{red}}$ ). For the electron transfer reaction, the free energy change from the singlet state $\left(\Delta \mathrm{G}^{\mathrm{S} 1}\right.$ Iod or $\left.\Delta \mathrm{G}^{\mathrm{S} 1}{ }_{\mathrm{EDB}}\right)$ could be calculated by $E_{\text {ox }}, E_{\text {red, }}$ and Es 1 according to equations 3 and $4 .{ }^{38}$ Similarly, the free energy change from the triplet state $\left(\Delta \mathrm{G}_{\mathrm{et}}\right)$ could be determined from equations 5 and $6^{38}$ using $E_{o x}, E_{\text {red, }}$ and $E_{T 1}$. Precisely, the triplet state energy level $\left(E_{T 1}\right)$ was extracted by molecular modelling (Gaussian 03). The reduction potentials of the iodonium salt and the oxidation potential of EDB used for the calculations were respectively of $-0.7 \mathrm{~V}^{39}$ and $1.0 \mathrm{~V}^{40}$, based on literature data.

$$
\begin{aligned}
& \Delta \mathrm{G}_{\text {Iod }}^{\mathrm{S} 1}=\mathrm{E}_{\mathrm{ox}}-(-0.7)-\mathrm{E}_{\mathrm{S} 1} \\
& \Delta \mathrm{G}^{\mathrm{S} 1}{ }_{\mathrm{EDB}}=1-\left(\mathrm{E}_{\mathrm{red}}\right)-\mathrm{E}_{\mathrm{S} 1} \\
& \Delta \mathrm{G}_{\text {Iod }}^{\mathrm{T} 1}=\mathrm{E}_{\mathrm{ox}}-(-0.7)-\mathrm{E}_{\mathrm{T} 1}
\end{aligned}
$$




$$
\Delta \mathrm{G}_{\mathrm{EDB}}^{\mathrm{T} 1}=1-\left(\mathrm{E}_{\mathrm{red}}\right)-\mathrm{E}_{\mathrm{T} 1}
$$

Radicals $\mathrm{Ar}^{\bullet}$ and $\mathrm{EDB}_{(-\mathrm{H})}$ generated from Iod and EDB during polymerization could be detected by Electron Spin Resonance-Spin Trapping experiments to confirm the proposed chemical mechanisms. Precisely, the solutions (dye/Iod or dye/EDB in tert-butylbenzene) were prepared as a weight content ratio $0.2 \mathrm{mg} / \mathrm{mL}$ for dyes and 2 $\mathrm{mg} / \mathrm{mL}$ for Iod or EDB and treated under a nitrogen saturated atmosphere at room temperature. Before irradiation, N-tert-butyl-phenylnitrone (PBN) was dissolved in solution as the spin trap agent and the weight content ratio was kept at $2 \mathrm{mg} / \mathrm{mL}$. Then, the radicals were monitored by X-band spectrometer (Bruker EMXplus) and the ESR spectra simulations were carried out using PEST WINSIM software. ${ }^{35,36}$

\subsection{Photocomposites preparation}

Photocomposites were prepared by dispersing a weight content of $20 \%$ silica fillers in photosensitive formulations, using three-component systems (composed by dye/Iod/EDB, $0.1 \mathrm{w} \% / 2 \% / 2 \%$, weight contents) dissolved in the monomer (TA) at room temperature and under air.

\subsection{D printing experiments}

Photosensitive monomer (TA) with PISs or PISs/silica was dropped onto a $2 \mathrm{~mm}$ thick homemade tank. Upon irradiation with a computer-controlled laser diode@405 $\mathrm{nm}$ with spot size around $50 \mu \mathrm{m}$, tridimensional patterns were fabricated. Their precise shapes were characterized by a numerical optical microscope (DSX-HRSU, OLYMPUS corporation) after direct laser writing.

\subsection{Computational procedure}

Geometry optimizations were performed at the B3LYP/6-31G* level using 
Gaussian G03 to determine the triplet state energy levels. Geometries were frequency checked. $^{41,42}$

\section{Results and Discussions}

\subsection{Synthesis of the different dyes}

All reagents and solvents were purchased from Aldrich, Alfa Aesar or TCI Europe and used as received without further purification. Mass spectroscopy was performed by the Spectropole of Aix-Marseille University. ESI mass spectral analyses were recorded with a 3200 QTRAP (Applied Biosystems SCIEX) mass spectrometer. The HRMS mass spectral analysis was performed with a QStar Elite (Applied Biosystems SCIEX) mass spectrometer. Elemental analyses were recorded with a Thermo Finnigan EA 1112 elemental analysis apparatus driven by the Eager 300 software. ${ }^{1} \mathrm{H}$ and ${ }^{13} \mathrm{C}$ NMR spectra were determined at room temperature in $5 \mathrm{~mm}$ o.d. tubes on a Bruker Avance 400 spectrometer and on a Bruker Avance 300 spectrometer of the Spectropole: The ${ }^{1} \mathrm{H}$ chemical shifts were referenced to the solvent peak $\mathrm{CDCl}_{3}(7.26 \mathrm{ppm})$ and the ${ }^{13} \mathrm{C}$ chemical shifts were referenced to the solvent peak $\mathrm{CDCl}_{3}(77 \mathrm{ppm})$.

Synthesis of 5-((1H-pyrrol-2-yl)methylene)-2,2-dimethyl-1,3-dioxane-4,6-dione 1

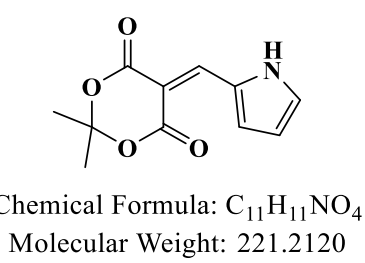

Meldrum acid (2,2-Dimethyl-1,3-dioxane-4,6-dione) (6.41 g, $44.47 \mathrm{mmol}, \mathrm{M}=144.13$ $\mathrm{g} / \mathrm{mol}$ ), $1 H$-pyrrole-2-carbaldehyde (4.22 g, $44.47 \mathrm{mmol}, \mathrm{M}=95.10 \mathrm{~g} / \mathrm{mol})$ were dissolved in ethanol $(50 \mathrm{~mL})$ and a few drops of pyridine were added. The solution was heated at reflux overnight, providing a precipitate. After cooling, it was filtered off, washed several times with ethanol and pentane, and dried under vacuum (8.66 g, 88\% yield). ${ }^{1} \mathrm{H}$ NMR $\left(\mathrm{CDCl}_{3}\right) \delta 1.76(\mathrm{~s}, 6 \mathrm{H}), 6.52-6.54(\mathrm{~m}, 1 \mathrm{H}), 7.10-7.12(\mathrm{~m}, 1 \mathrm{H}), 7.42-$ $7.44(\mathrm{~m}, 1 \mathrm{H}), 8.27(\mathrm{~s}, 1 \mathrm{H}), 12.70(\mathrm{brs}, 1 \mathrm{H}, \mathrm{NH}) ;{ }^{13} \mathrm{C} \mathrm{NMR}\left(\mathrm{CDCl}_{3}\right) \delta 27.2,100.4,104.3$, 
114.5, 128.8, 130.2, 131.9, 143.4, 164.2, 164.4; HRMS (ESI MS) m/z: theor: 221.0688 found: $221.0691\left(\mathrm{M}^{+}\right.$detected).

Synthesis of 2-(3-oxo-2-(thiophen-2-ylmethylene)-2,3-dihydro-1H-inden-1-ylidene) malononitrile 2

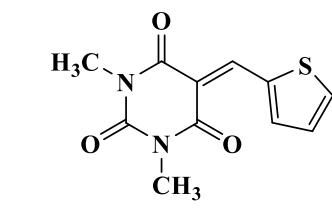

Chemical Formula: $\mathrm{C}_{11} \mathrm{H}_{10} \mathrm{~N}_{2} \mathrm{O}_{3} \mathrm{~S}$

Molecular Weight: 250.2720

1,3-Dimethylpyrimidine-2,4,6(1H,3H,5H)-trione $(6.94 \mathrm{~g}, 44.47 \mathrm{mmol}, \mathrm{M}=156.14$ $\mathrm{g} / \mathrm{mol}$ ) and 2-thiophenecarboxaldehyde ( $5 \mathrm{~g}, 44.47 \mathrm{mmol}, \mathrm{M}=112.15 \mathrm{~g} / \mathrm{mol})$ were dissolved in ethanol $(50 \mathrm{~mL})$ and a few drops of pyridine were added. The solution was heated at reflux overnight, providing a precipitate. After cooling, it was filtered off, washed several times with ethanol and pentane, and dried under vacuum $(9.35 \mathrm{~g}, 84 \%$ yield). ${ }^{1} \mathrm{H}$ NMR $\left(\mathrm{CDCl}_{3}\right) \delta 3.42$ (s, 3H), 3.43 (s, 3H), 7.29 (dd, 1H, J = 5.1 Hz, J = 3.9 $\mathrm{Hz}), 7.90-7.91(\mathrm{~m}, 1 \mathrm{H}), 7.99-8.02(\mathrm{~m}, 1 \mathrm{H}), 8.75(\mathrm{~d}, 1 \mathrm{H}, \mathrm{J}=0.7 \mathrm{~Hz}) ;{ }^{13} \mathrm{C} \mathrm{NMR}\left(\mathrm{CDCl}_{3}\right)$ $\delta 28.1,28.9,110.6,128.2,137.0,141.8,145.4,149.0,151.3,161.7,162.6$; HRMS (ESI MS) $\mathrm{m} / \mathrm{z}$ : theor: 250.0412 found: $250.0410\left(\mathrm{M}^{+}\right.$detected $)$.

Synthesis of 5-((1H-pyrrol-2-yl)methylene)-1,3-dimethylpyrimidine-2,4,6(1H,3H,5H)trione 3

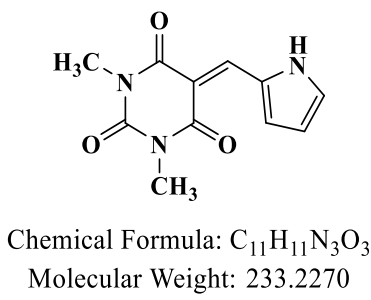

1,3-Dimethylpyrimidine-2,4,6(1H,3H,5H)-trione $(6.94 \mathrm{~g}, 44.47 \mathrm{mmol}, \mathrm{M}=156.14$ $\mathrm{g} / \mathrm{mol}$ ) and $1 H$-pyrrole-2-carbaldehyde (4.22 g, $44.47 \mathrm{mmol}, \mathrm{M}=95.10 \mathrm{~g} / \mathrm{mol})$ were 
dissolved in ethanol $(50 \mathrm{~mL})$ and a few drops of pyridine were added. The solution was heated at reflux overnight, providing a precipitate. After cooling, it was filtered off, washed several times with ethanol and pentane, and dried under vacuum $(8.09 \mathrm{~g}, 78 \%$ yield). ${ }^{1} \mathrm{H}$ NMR $\left(\mathrm{CDCl}_{3}\right) \delta 3.40(\mathrm{~s}, 3 \mathrm{H}), 3.42(\mathrm{~s}, 3 \mathrm{H}), 6.53-6.55(\mathrm{~m}, 1 \mathrm{H}), 7.13-7.15(\mathrm{~m}$, 1H), 7.40-7.41 (m, 1H), 13.28 (brs, $1 \mathrm{H}, \mathrm{NH}) ;{ }^{13} \mathrm{C} \mathrm{NMR}\left(\mathrm{CDCl}_{3}\right) \delta$ 28.3, 28.8, 105.6, 114.6, 129.5, 130.0, 131.3, 142.9, 151.5, 163.3, 163.7; HRMS (ESI MS) m/z: theor: 233.0800 found: $233.0802\left(\mathrm{M}^{+}\right.$detected).

Synthesis of 2-(3-oxo-2-(thiophen-2-ylmethylene)-2,3-dihydro-1H-inden-1-ylidene) malononitrile 4

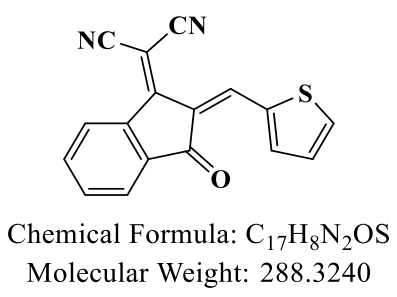

2-(3-Oxo-2,3-dihydro-1H-inden-1-ylidene)malononitrile $(8.63 \mathrm{~g}, 44.47 \mathrm{mmol}, \mathrm{M}=$ $194.19 \mathrm{~g} / \mathrm{mol}$ ) and 2-thiophenecarboxaldehyde (5 g, $44.47 \mathrm{mmol}, \mathrm{M}=112.15 \mathrm{~g} / \mathrm{mol}$ ) were dissolved in ethanol $(50 \mathrm{~mL})$ and a few drops of pyridine were added. The solution was heated at reflux overnight, providing a precipitate. After cooling, it was filtered off, washed several times with ethanol and pentane, and dried under vacuum (11.67 g, 91\% yield). ${ }^{1} \mathrm{H}$ NMR $\left(\mathrm{CDCl}_{3}\right) \delta 7.30(\mathrm{dd}, 1 \mathrm{H}, \mathrm{J}=4.0 \mathrm{~Hz}, \mathrm{~J}=5.0 \mathrm{~Hz}), 7.77-7.85(\mathrm{~m}, 2 \mathrm{H})$, 7.94-8.01 (m, 3H), 8.73-8.75 (m, 1H), $8.96(\mathrm{~s}, 1 \mathrm{H}) ;{ }^{13} \mathrm{C} \mathrm{NMR}\left(\mathrm{CDCl}_{3}\right) \delta$ 71.0, 114.0, $114.2,123.9,124.1,125.5,128.6,134.8,135.4,137.0,137.1,138.3,139.9,141.2,144.3$, 160.6, 187.9; HRMS (ESI MS) m/z: theor: 288.0357 found: $288.0352\left(\mathrm{M}^{+}\right.$detected).

Synthesis of 2,2'-(2-((1H-pyrrol-2-yl)methylene)-1H-indene-1,3(2H)-diylidene) dimalononitrile 5 


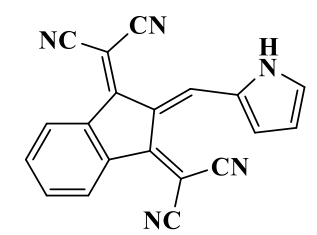

Chemical Formula: $\mathrm{C}_{20} \mathrm{H}_{9} \mathrm{~N}_{5}$ Molecular Weight: 319,3270

2,2'-(1H-Indene-1,3(2H)-diylidene)dimalononitrile (2 g, $8.25 \mathrm{mmol}, \mathrm{M}=242.24 \mathrm{~g} / \mathrm{mol})$ and 2-pyrrolecarboxaldehyde $(0.78 \mathrm{~g}, 8.25 \mathrm{mmol}, \mathrm{M}=95.10 \mathrm{~g} / \mathrm{mol})$ were dissolved in acetic anhydride $(50 \mathrm{~mL})$ and the solution was heated at $100^{\circ} \mathrm{C}$ for 2 hours. A red precipitate formed. After cooling, it was filtered off, washed several times with ether, then pentane and dried under vacuum $\left(2.26 \mathrm{~g}, 86 \%\right.$ yield). ${ }^{1} \mathrm{H}$ NMR (DMSO-d 6 ) $66.56-$ $6.57(\mathrm{~m}, 1 \mathrm{H}), 7.28-7.29(\mathrm{~m}, 1 \mathrm{H}), 7.70-7.71(\mathrm{~m}, 1 \mathrm{H}), 7.91-7.93(\mathrm{~m}, 2 \mathrm{H}), 8.35(\mathrm{~s}, 1 \mathrm{H})$, 8.41-8.43 (m, 2H); ${ }^{13} \mathrm{C}$ NMR (DMSO-d 6 ) $\delta$ 69.6, 114.0, 114.6, 115.2, 121.1, 124.6, 129.1, 132.1, 134.1, 137.2, 161.5, 167.0; HRMS (ESI MS) m/z: theor: 319.0858 found: $319.0855\left(\mathrm{M}^{+}\right.$detected $)$.

Synthesis of [1,2']Biindenylidene-3,1',3'-trione 6

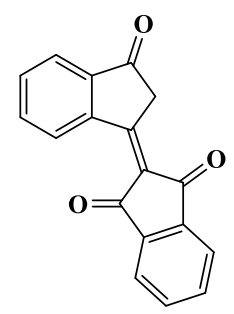

Chemical Formula: $\mathrm{C}_{18} \mathrm{H}_{10} \mathrm{O}_{3}$ Molecular Weight: 274.2750

A solution of 1,3-indanedione $(2.04 \mathrm{~g}, 14.0 \mathrm{mmol})$ in absolute ethanol $(25 \mathrm{~mL})$ was stirred for $5 \mathrm{~min}$, before $\mathrm{NaOAc}(1.53 \mathrm{~g}, 18.6 \mathrm{mmol})$ was added. After $1 \mathrm{~h}$ of stirring at room temperature, the reaction mixture was diluted with $\sim 50 \mathrm{~mL}$ of water. The solution was acidified with conc. $\mathrm{HCl}$ to a $\mathrm{pH}$ of $\sim 1$, the green precipitate was filtered off and dried under vacuum $\left(1.55 \mathrm{~g}, 81 \%\right.$ yield). ${ }^{1} \mathrm{H}$ NMR $\left(\mathrm{CDCl}_{3}\right) \delta 4.17$ (s, 2H), 7.73-7.77 (m, 1H), 7.81-7.88 (m, 3H), 7.94-7.98 (m, 2H), 8.01-8.03 (m, 1H), $9.68(\mathrm{~m}, 1 \mathrm{H}, \mathrm{J}=8.1$ 
$\mathrm{Hz}) ;{ }^{13} \mathrm{C} \mathrm{NMR}\left(\mathrm{CDCl}_{3}\right) \delta 43.4,123.1,123.4,123.5,125.9,131.7,134.2,135.3,135.3$, 135.4, 140.5, 141.3, 141.7, 145.9, 155.4, 189.4, 191.1, 200.9; HRMS (ESI MS) m/z: theor: 274.0630 found: $274.0633\left(\mathrm{M}^{+}\right.$detected).

\subsection{Photopolymerization kinetics with the newly proposed push-pull dyes in three- component photoinitiating systems}

Photopolymerization profiles of TA obtained with three-component photoinitiating systems (PISs) upon irradiation with a LED at $405 \mathrm{~nm}$ are shown in Figure 2a. By using Real-Time Fourier Transform Infrared spectroscopy (RT-FTIR) at room temperature, the acrylate function conversion could be monitored and the final function conversions (FCs) obtained after $400 \mathrm{~s}$ of irradiation in the presence of different dye-based PISs are gathered in the Table 1. Here, a two-component PIS (2\% Iod: $2 \%$ amine in TA) without dyes (cited as dye $0 /$ blank in Table 1) was used as a reference system to make a comparison with the three-component systems. Indeed, dyes 1-6 showed different performances with the same content of co-initiators (Iod and EDB), indicating their different photoinitiation abilities. To clarify the results more clearly, we divided the investigated dyes into three different families:

(1) For dyes 5 and 6, high final acrylate function conversions (FCs) reaching 98\% or above could be obtained, what is higher than the conversions obtained with the reference two-component Iod/EDB PISs without dye. In this last case, a final acrylate function conversion of $97 \%$ could be determined after $50 \mathrm{~s}$ of irradiation (set as curve 0 in Figure 2a or blank in Table 1). The initiation ability for this latter blank is ascribed to the formation to a photosensitive charge transfer complex between amine and iodonium salt. ${ }^{43}$

(2) For dye 1 and 3, even if these dyes showed lower efficiencies and lower FCs compared to dyes 5, 6 or blank, however, their polymerization processes were also characterized by shorter induction period ( $\mathrm{T}-\mathrm{T}_{0}$ with $\mathrm{T}$ : Start time of polymerization; $\mathrm{T}_{0}$ : Start time of light irradiation). Precisely, their polymerizations were started within 10s, 
i.e. $7 \mathrm{~s}$ for dye 1 and $4 \mathrm{~s}$ for dye 3 while $40 \mathrm{~s}$ for the blank. Thus, their remarkable photoinitiation abilities were also considered and investigated in the following context. Interestingly, a short induction period (25s) was also obtained with dye 6 , which furnished the highest acrylate function conversion ( $99 \%)$. This is undoubtedly the most efficient photoinitiator of the series of dyes examined in this work.

(3) The other dyes (dyes 2 and 4) showed both poor efficiencies (lowest FCs) or longer induction periods compared to the other dyes: The acrylate function conversion obtained with dye 2 only furnished $73 \%$ and the induction period was $68 \mathrm{~s}$; On the other hand, even if the induction period for the FRP process is quite short (4 s) using dye 4based PIS at $405 \mathrm{~nm}$, a relatively low FCs was obtained in these conditions, compared to the $97 \%$ of acrylate function conversion obtained by initiation with the reference two-component PIS (Iod/EDB without dye). Thus, dyes 2 and 4 were thus excluded from the following investigations e.g. the chemical mechanisms and the light absorption properties.
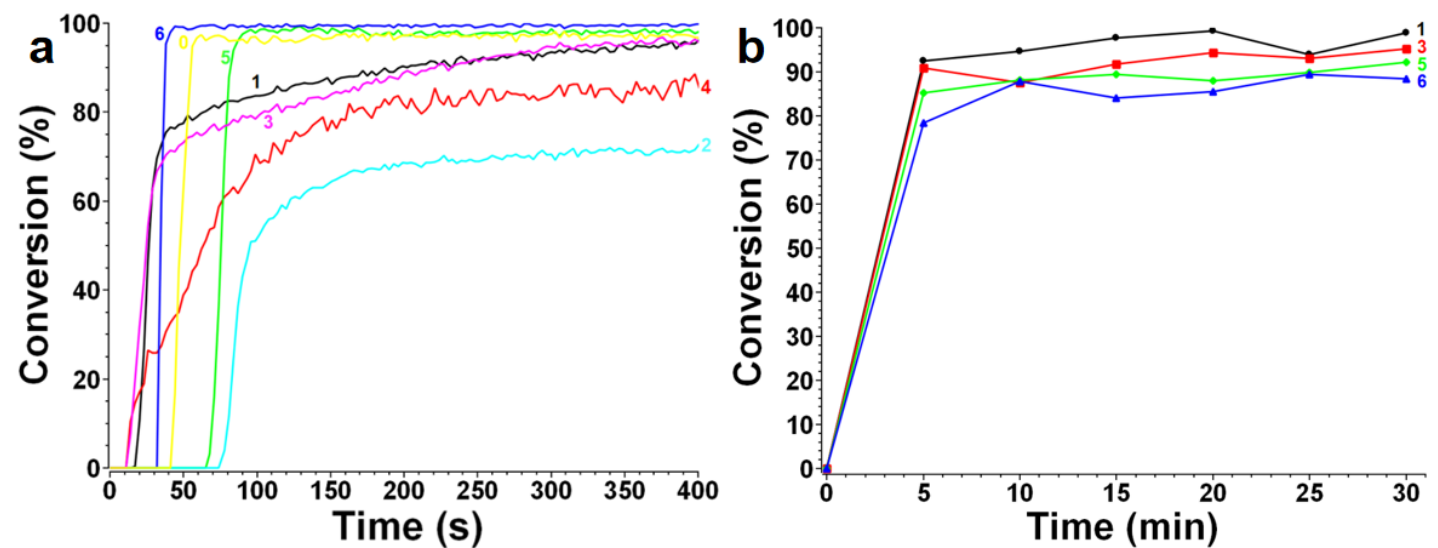

Figure 2. (a) Photopolymerization profiles of $\mathrm{TA}$ (conversion of $\mathrm{C}=\mathrm{C}$ bonds vs irradiation time) initiated by iodonium salts and EDB upon exposure to LED@405nm in laminate in the presence of dyes 1-6 at the same weight ratio: dye:Iod:EDB $=0.1 \%: 2 \%: 2 \%$ in TA. Curve 0 : Iodonium salt: $\mathrm{EDB}=2 \%: 2 \%$ in TA without dye. The curve number 1-6 corresponds to the number of dye 1-6. The irradiation starts for $\mathrm{t}=\mathrm{XX}$ s. (b) Photopolymerization profiles of $\mathrm{TA}$ (conversion of $\mathrm{C}=\mathrm{C}$ bonds vs irradiation time) initiated by the iodonium salt and EDB upon exposure to sunlight in laminate in the presence of dyes at the weight ratio: dye:Iod:EDB=0.1\%:2\%:2\% in TA. (black) dye 1 ; (red) dye 
3; (green) dye 5; (blue) dye 6.

In addition, the polymerization of TA initiated by dyes 1, 3, 5 and 6-based PISs including iodonium salt or amine was also established upon sunlight irradiation. The photopolymerization kinetics are depicted in Figure 2b. Markedly, these four push-pull dyes furnished high performances for the polymerization of TA under sunlight, demonstrating high final reactive function conversions (FCs): $\sim 99 \%$ for dye 1 (black curve), $\sim 95 \%$ for dye 3 (red curve), $\sim 92 \%$ for dye 5 (green curve), and $\sim 88 \%$ for dye 6 (blue curve), evidencing that these dyes can also act as efficient photoinitiators under natural light source and other mild conditions. Thus, an order of final conversions with these four dyes under sunlight exposure could be established: dye $1>$ dye $3>$ dye $5>$ dye 6. Obviously, dyes 1 and 3 demonstrated better photoinitiation efficiencies compared to that of dyes 5 and 6 . In conclusion, high photoinitiation abilities can be achieved by irradiation of sunlight in the presence of the investigated dyes as light harvesting compounds.

Table 1. Summary of the final acrylate function conversions (FCs) at $405 \mathrm{~nm}$ and sunlight (dyes 1, 3, 5, 6 at sunlight included) for TA using three-component photoinitiating systems: dyes $(0.1 \%, \mathrm{w} / \mathrm{w}) /$ iodonium salt $(2 \%, \mathrm{w} / \mathrm{w}) / \mathrm{amine}(2 \%, \mathrm{w} / \mathrm{w})$.

\begin{tabular}{|l|c|c|c|}
\hline No. & Push-pull dyes & Conversion at 405 LED & Conversion at sunlight \\
\hline 1 &
\end{tabular}




\begin{tabular}{|l|l|l|l|}
\hline 2 & $\sim 73 \%$ & - \\
\hline 4
\end{tabular}

\subsection{Photochemical properties of push-pull dyes}

\subsubsection{Light absorption properties of the push-pull dyes}

Light absorption properties such as the molar extinction coefficients at the maximum absorption wavelengths $\left(\lambda_{\max }\right)$ and the molar extinction coefficients at the $405 \mathrm{~nm}\left(\varepsilon_{405 \mathrm{~nm}}\right)$ were determined for all dyes, and the relevant results are gathered in the 
Table 2. In addition, their UV-visible spectra are illustrated in Figure 3. Dyes can be divided into three families, based on their maximum molar extinction coefficients at the maximum absorption wavelengths $\left(\lambda_{\max }\right)$ : (1) Thus, the first group showed the highest maximum molar extinction coefficients $\left(\lambda_{\max }\right)$ with values of $50990 \mathrm{M}^{-1} . \mathrm{cm}^{-1}$ at $\lambda_{\max }=$ $391 \mathrm{~nm}$ for dye 1 and $55460 \mathrm{M}^{-1} . \mathrm{cm}^{-1} \lambda_{\max }=404 \mathrm{~nm}$ for dye 3 . These data support the high photoinitiation abilities evidenced for dyes 1 and 3 under exposure to both $405 \mathrm{~nm}$ LED and sunlight; (2) the second group identified as exhibiting a lower efficiency than that of the first group also showed lower extinction coefficients. Thus, molar extinction coefficients of $27740 \mathrm{M}^{-1} . \mathrm{cm}^{-1}$ at $\lambda_{\max }=368 \mathrm{~nm}$ for dye 2 and $28310 \mathrm{M}^{-1} . \mathrm{cm}^{-1}$ at $\lambda_{\max }=$ $430 \mathrm{~nm}$ for dye 4 could be determined; (3) Interestingly, dyes 5 and 6 showed the smallest extinction coefficients at the maximum absorption wavelengths among all dyes: $10490 \mathrm{M}^{-1} . \mathrm{cm}^{-1}$ at $\lambda_{\max }=473 \mathrm{~nm}$ for dye $5,7600 \mathrm{M}^{-1} . \mathrm{cm}^{-1}$ at $\lambda_{\max }=512 \mathrm{~nm}$ for dye 6 which was not in agreement with their high photoinitiation abilities as discussed in the polymerization profiles.

Parallel to this, all push-pull dyes were also investigated for their molar extinction coefficients $\left(\boldsymbol{\varepsilon}_{405 \mathrm{~nm}}\right)$ at $405 \mathrm{~nm}$. For group (1), relatively high molar extinction coefficients were found at $405 \mathrm{~nm}$ for dyes 1 and 3 (standing at $\varepsilon_{\max }=17680 \mathrm{M}^{-1} \cdot \mathrm{cm}^{-1}$ for dye 1 and $\varepsilon_{\text {max }}=55350 \mathrm{M}^{-1} . \mathrm{cm}^{-1}$ for dye 3), which is consistent to their high performances in free radical polymerization at $405 \mathrm{~nm}$. In the case of group (3), both poor molar extinction coefficients at $405 \mathrm{~nm}$ were found for dye 5 and $6\left(\varepsilon_{\max }=5590\right.$ $\left.\mathrm{M}^{-1} \cdot \mathrm{cm}^{-1}, \varepsilon_{@ 405 \mathrm{~nm}}=2380 \mathrm{M}^{-1} \cdot \mathrm{cm}^{-1}\right)$, indicating that these two dyes acted as poor photoinitiators in free radical polymerization under exposure to both $405 \mathrm{~nm}$ LED and sunlight. Interestingly, dye 4 showed a high molar extinction coefficient $\left(\boldsymbol{\varepsilon}_{405 \mathrm{~nm}}=21820\right.$ $\mathrm{M}^{-1} \cdot \mathrm{cm}^{-1}$ ), even if a poor polymerization efficiency was found for dye 4-based PIS. Oppositely, a relatively low molar extinction coefficient at $405 \mathrm{~nm}$ was found for dye 2 $\left(\varepsilon_{405 \mathrm{~nm}}=4010 \mathrm{M}^{-1} \cdot \mathrm{cm}^{-1}\right)$, consistent with its poor photoinitiation ability observed during polymerization, even though dye 2 exhibited similar molar maximum extinction 
coefficient $\left(\boldsymbol{\varepsilon}_{\max }=27740 \mathrm{M}^{-1} \cdot \mathrm{cm}^{-1}\right)$ compared to that of dye 4 .

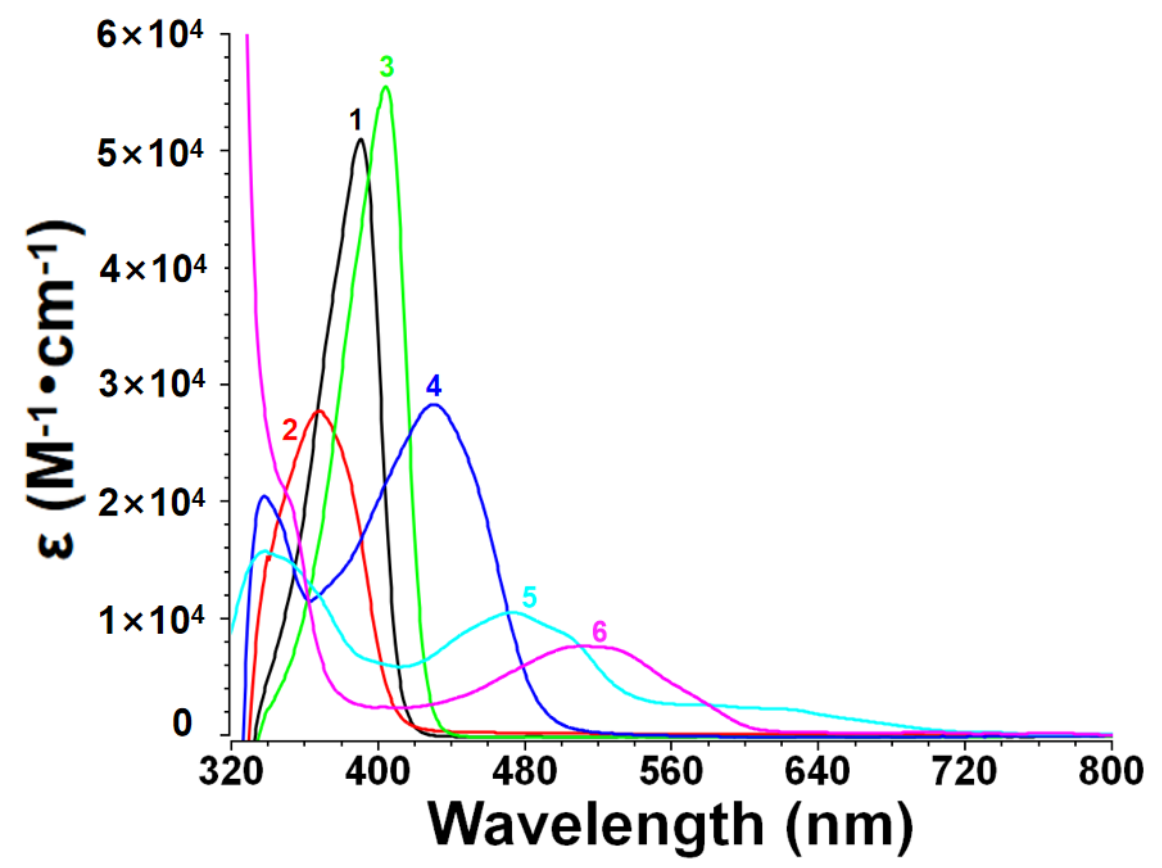

Figure 3. UV-visible absorption spectra in acetonitrile of the push-pull dyes (dye 1-6) in acetonitrile. The curve number 1-6 corresponds to the dye 1-6.

Table 2. Light absorption properties of the different push-pull dyes in acetonitrile: maximum absorption wavelengths $\lambda_{\max }$; molar extinction coefficients at $\lambda_{\max }\left(\varepsilon_{\max }\right)$ and extinction coefficients at the emission wavelength of the LED@405 nm( $\left.\varepsilon_{@ 405 n m}\right)$.

\begin{tabular}{|c|c|c|c|}
\hline & $\boldsymbol{\lambda}_{\text {max }}(\mathbf{n m})$ & $\boldsymbol{\varepsilon}_{\mathbf{m a x}}\left(\mathbf{M}^{\mathbf{- 1}} \mathbf{. c m}{ }^{-\mathbf{1}}\right)$ & $\boldsymbol{\varepsilon}_{@ \mathbf{4 0 5 n m}}\left(\mathbf{M}^{\mathbf{- 1}} . \mathbf{c m} \mathbf{~}^{\mathbf{1}}\right)$ \\
\hline Dye 1 & 391 & 50990 & 17680 \\
\hline Dye 2 & 368 & 27740 & 4010 \\
\hline Dye 3 & 404 & 55460 & 55350 \\
\hline
\end{tabular}




\begin{tabular}{|c|c|c|c|}
\hline Dye 4 & 430 & 28310 & 21820 \\
\hline Dye 5 & 473 & 10490 & 5990 \\
\hline Dye 6 & 512 & 7600 & 2380 \\
\hline
\end{tabular}

\subsubsection{Steady state photolysis experiments of dye-based Photoinitiating Systems}

Interactions between dye, Iod and EDB in three-component systems were examined by steady state photolysis experiments upon irradiation with the LED@405 $\mathrm{nm}$. In addition, the interactions of dye/Iod or dye/EDB were also investigated, and comparisons between the consumption of dyes both in three-component systems dye/Iod/EDB and two-component systems dye/Iod (or dye/EDB) were also established to confirm the chemical mechanisms occurring during polymerization. Here, the solutions were prepared at $1.23 \times 10^{-5} \mathrm{M}$ dye 5 or $1.44 \times 10^{-5} \mathrm{M}$ dye $6,2.93 \times 10^{-2} \mathrm{M}$ Iod and/or $8.15 \times 10^{-2} \mathrm{M}$ EDB in acetonitrile. Investigations concerning the photolysis of the two-component systems (dye/Iod and dye/EDB) in solution were highly consistent to the interactions existing in three-component systems, which will be discussed in the following part concerning the chemical mechanism. 

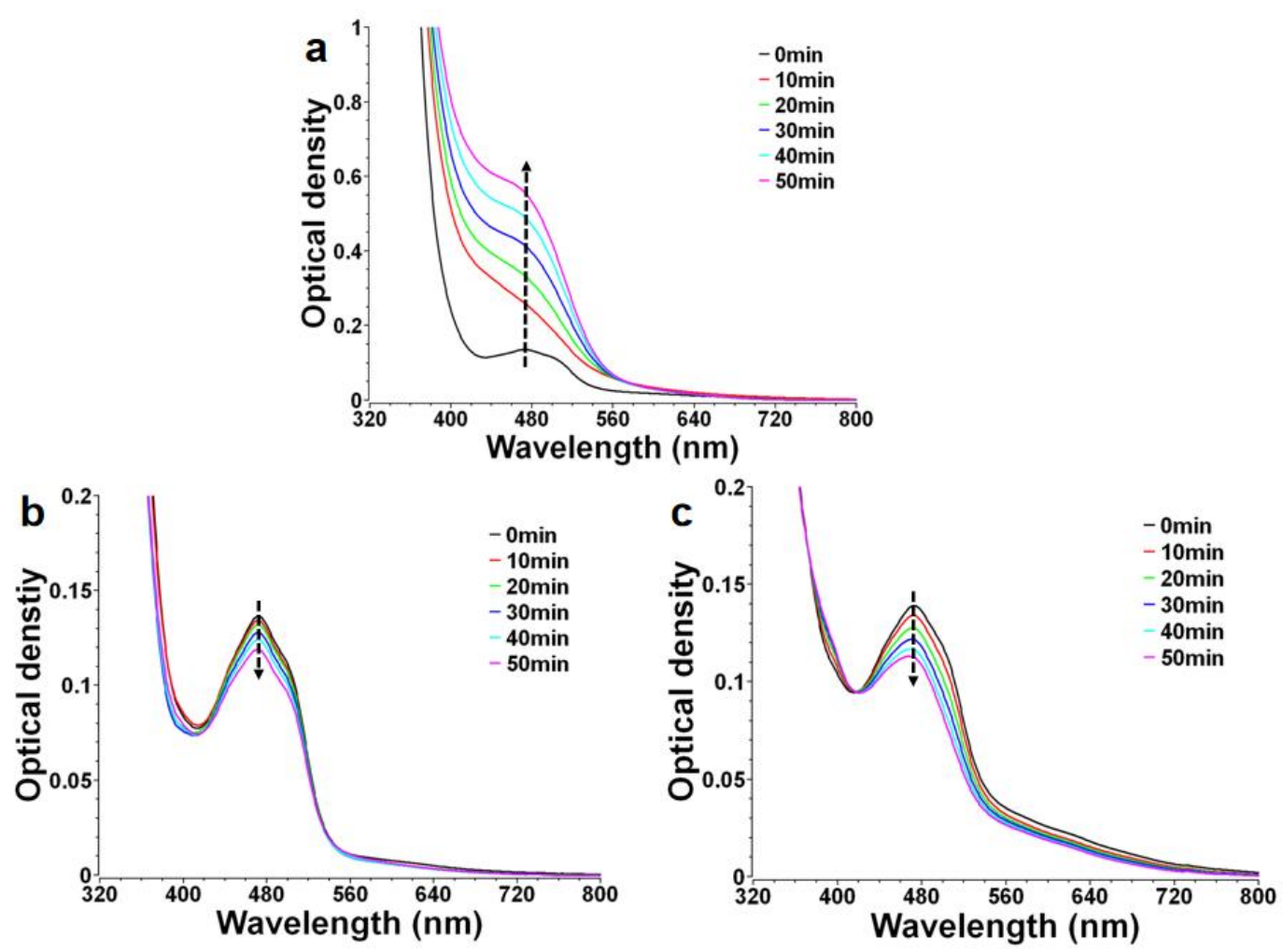

Figure 4. UV-visible absorption spectra of dye $5\left(1.23 \times 10^{-5} \mathrm{M}\right)$ with co-initiators in acetonitrile: (a) $\operatorname{Iod}\left(2.93 \times 10^{-2} \mathrm{M}\right)$ and $\operatorname{EDB}\left(8.15 \times 10^{-2} \mathrm{M}\right)$, (b) $\operatorname{Iod}\left(2.93 \times 10^{-2} \mathrm{M}\right)$, (c) $\operatorname{EDB}\left(8.15 \times 10^{-2} \mathrm{M}\right)$ upon exposure to LED@405nm under air for different time.

Firstly, the UV-visible absorption spectra of the dye 5-based three-component system increased when the $405 \mathrm{~nm}$ LED was used as irradiation source, even if decreasing tendencies were observed from dye 5/Iod and dye 5/EDB two-component systems (see Figure 4). The results indicated a new photoproduct was generated during the irradiation process for the three-component system (See Figure 4a). This phenomenon was also observed in the case of dyes 1 and 3 (Figure S1a, b), indicating the same chemical mechanisms occurred with these three dyes during photopolymerization. However, dye 5 was consumed in dye 5/Iod and dye 5/EDB as shown in Figure $4 \mathrm{~b}$ and $\mathrm{c}$, proving the formation of new photoproducts existed under participation of the radicals obtained from the interactions between dye/ Iod and dye/EDB.

Dye 6/Iod/EDB three-component system showed a decreasing photolysis process 
which is distinct from that observed for dye 5/Iod/EDB (see Figure 5). The twocomponent systems (dye/Iod and dye/EDB) showed similar behaviors than the threecomponent systems during the photolysis while the consumption of dye 6 threecomponent system and two-component systems were also illustrated to investigate the chemical mechanisms in detail (see Figure 5d). Even if the decreasing tendencies were also detected from the photolysis of dye 6/EDB, however, the consumption of dye 6 in dye 6/Iod system achieved higher level ( $\sim 30 \%)$ than that of dye 6/EDB system (4\%). Remarkably, both of their photolysis drastically contribute to the integrated interactions in three-component systems which the consumption of dye 6 reached higher percentage ( $\sim 4 \%$ ) at the end of irradiation ( 100s), and higher efficiency of dye 6/Iod interaction gave more contributions when compared to the dye 6/EDB interaction in free radical polymerization process.
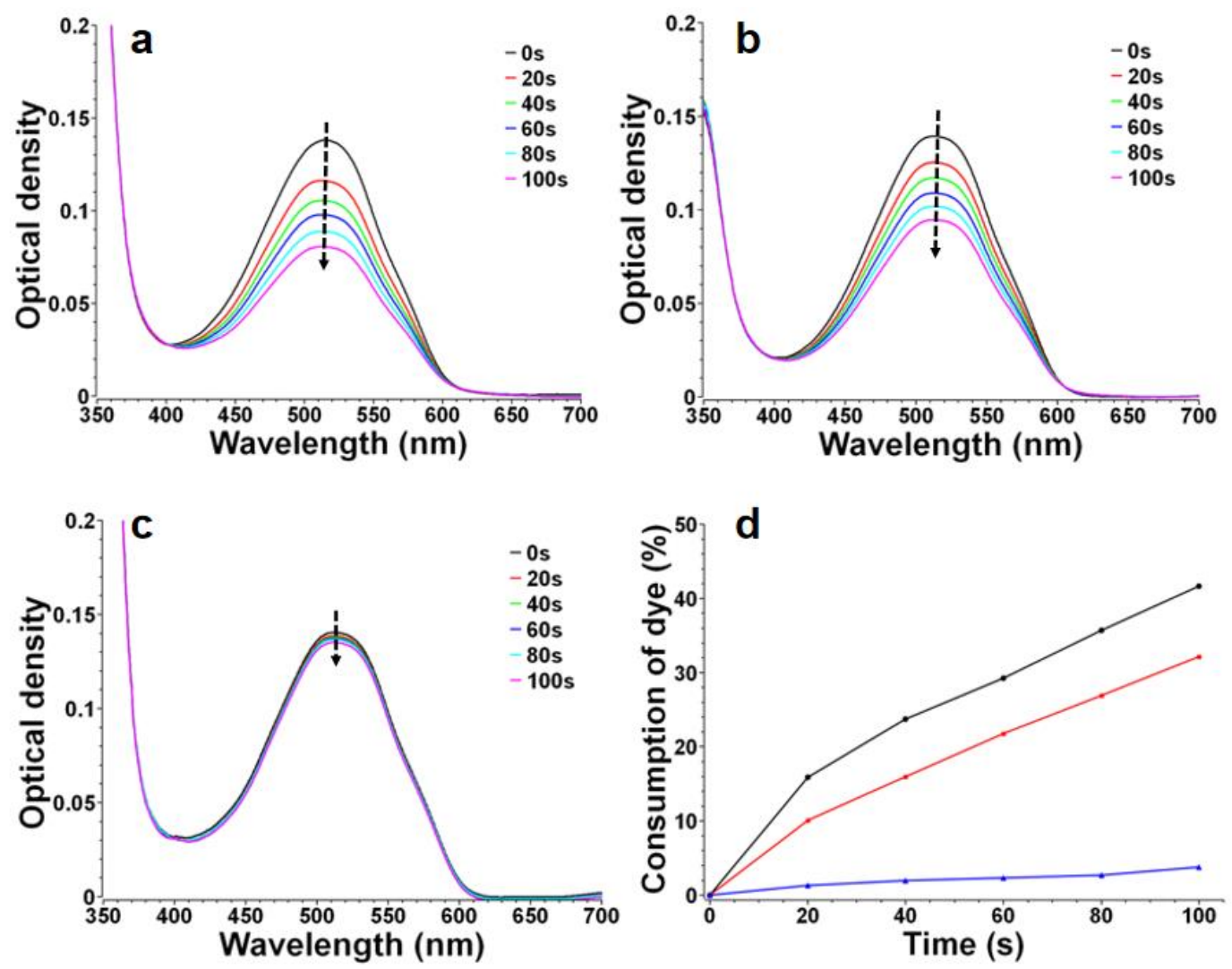

Figure 5. UV-visible absorption spectra of dye $6\left(1.44 \times 10^{-5} \mathrm{M}\right)$ with co-initiators in acetonitrile: (a) $\operatorname{Iod}\left(2.93 \times 10^{-2} \mathrm{M}\right)$ and $\operatorname{EDB}\left(8.15 \times 10^{-2} \mathrm{M}\right)$, (b) $\operatorname{Iod}\left(2.93 \times 10^{-2} \mathrm{M}\right)$ and 
(c) $\operatorname{EDB}\left(8.15 \times 10^{-2} \mathrm{M}\right)$ upon exposure to LED@405nm under air for different time. (d) Consumption of dye 6 vs. irradiation time under the irradiation of LED@ 405 nm: dye 6/Iod/EDB(•); dye 6/Iod(ם); dye 6/EDB( $\mathbf{\Delta})$.

\subsubsection{Chemical mechanisms}

According to the previous reports, ${ }^{10,44}$ the chemical mechanisms involved with the push-pull dye-based PISs were determined and presented in Scheme 3. First, the ground states of dyes were converted to the excited states (dye*) under irradiation, then dye* can react with Iod or EDB in two different reactions as r2, r3, respectively. The oxidation reaction $\mathrm{r} 2$ could generate radical Dye ${ }^{\bullet+}$ which can be reduced by EDB in the next step, regenerating the dye in its initial state (See r3). On the other hand, the original form of dyes also can be regenerated from Dye- $\mathrm{H}^{\bullet}$ to finalize the catalytic cycle when Dye-H ${ }^{\bullet}$ was oxidized by Iod as well. Notably, the radicals $\mathrm{Ar}^{\bullet}$ and $\mathrm{EDB}^{\bullet}{ }_{(-\mathrm{H})}$ can be generated from two different reactions $\mathrm{r} 4, \mathrm{r} 5$ (see Scheme 3) and can be detected by ESR-spin trapping experiments (see below), which confirmed the supposed chemical mechanisms discussed in this section.

(r1) Dye $\rightarrow *$ Dye $\quad(h v)$

(r2) $\quad *$ Dye $+\mathrm{Ar}_{2} \mathrm{I}^{+} \rightarrow \mathrm{Dye}^{\bullet+}+\mathrm{Ar}_{2} \mathrm{I}^{\bullet} \rightarrow \mathrm{Dye}^{\bullet+}+\mathrm{Ar} \bullet^{\bullet} \mathrm{ArI}$

(r3) $\quad *$ Dye $+\mathrm{EDB} \rightarrow \mathrm{Dye}^{\bullet-}+\mathrm{EDB}^{\bullet+} \rightarrow \mathrm{Dye}^{-\mathrm{H}^{\bullet}}+\mathrm{EDB}^{\bullet}{ }_{(-\mathrm{H})}$

(r4) $\quad \mathrm{Dye}^{\bullet+}+\mathrm{EDB} \rightarrow$ Dye $+\mathrm{EDB}^{\bullet+}$

(r5) $\quad$ Dye- $\mathrm{H}^{\bullet}+\mathrm{Ar}_{2} \mathrm{I}^{+} \rightarrow$ Dye $+\mathrm{Ar}^{\bullet}+\mathrm{ArI}+\mathrm{H}^{+}$

Scheme 3. Proposed photoinitiation step mechanisms of the dyes/Iod/EDB redox combination.

As showed in Figure 6, the electron transfer of dyes 3, 6, 7, and 8 was investigated in Cyclic Voltammetry experiments. The oxidation potentials $\left(E_{o x}\right)$ and the reduction 
potentials $\left(\mathrm{E}_{\mathrm{red}}\right)$ of dyes $1,3,5$, and 6 were calculated from the half peak potentials in oxidation and reduction cyclic from their cyclic voltammograms (Table 3). No current was detected in the reduction cycle of dye 1 (see Figure 6a), indicating that its reduction potential is probably less than $-2.00 \mathrm{~V}$.

The singlet excited state energies $\left(\mathrm{E}_{\mathrm{S} 1}\right)$ of dyes were calculated from the crossing point between the normalized UV-visible absorption and normalized fluorescence spectra of dye in acetonitrile solutions (see Figure S2). The different values are gathered in Table 3. After that, on the basis of chemical parameters such as the oxidation potential $\left(E_{o x}\right)$, the reduction potential $\left(E_{\text {red }}\right)$ and the singlet excited state energy $\left(E_{S 1}\right)$, it was possible to calculate the free energy changes $\Delta \mathrm{G}^{\mathrm{S} 1}{ }_{\text {Iod }}$ or $\Delta \mathrm{G}^{\mathrm{S} 1}{ }_{\mathrm{EDB}}$ for the electron transfer reaction in dye/Iod and dye/EDB systems according to equations (eq. 3-6). All the results were lower than 0 , and the data are gathered in Table 3 (e.g. $\Delta \mathrm{G}_{\mathrm{Iod}}=-2.09 \mathrm{eV}$, $\Delta \mathrm{G}_{\mathrm{EDB}}>-0.07 \mathrm{eV}$ for dye $1 ; \Delta \mathrm{G}_{\mathrm{Iod}}=-2.02 \mathrm{eV}, \Delta \mathrm{G}_{\mathrm{EDB}}=-0.64 \mathrm{eV}$ for dye $3 ; \Delta \mathrm{G}_{\mathrm{Iod}}=-1.22 \mathrm{eV}$, $\Delta \mathrm{G}_{\mathrm{EDB}}=-0.82 \mathrm{eV}$ for dye $5 ; \Delta \mathrm{G}_{\mathrm{Iod}}=-1.05 \mathrm{eV}, \Delta \mathrm{G}_{\mathrm{EDB}}=--0.31 \mathrm{eV}$ for dye 6), indicating the theoretical feasibility of the electron transfer reactions.

Calculations of the triplet energy levels $\mathrm{E}_{\mathrm{T} 1}(\mathrm{eV})$ of dyes 1, 3, 5, and 6 were performed at the DFT level (Table 3). The triplet routes involved in the mechanisms can probably be ruled out for the dye/EDB interactions due to the positive values of their free energy changes at the triplet state $\Delta \mathrm{Get}^{\mathrm{T} 1}$ (as exception of dye 6/EDB). In contrast, the ${ }^{3}$ dye/Iod interactions were all favorable. 

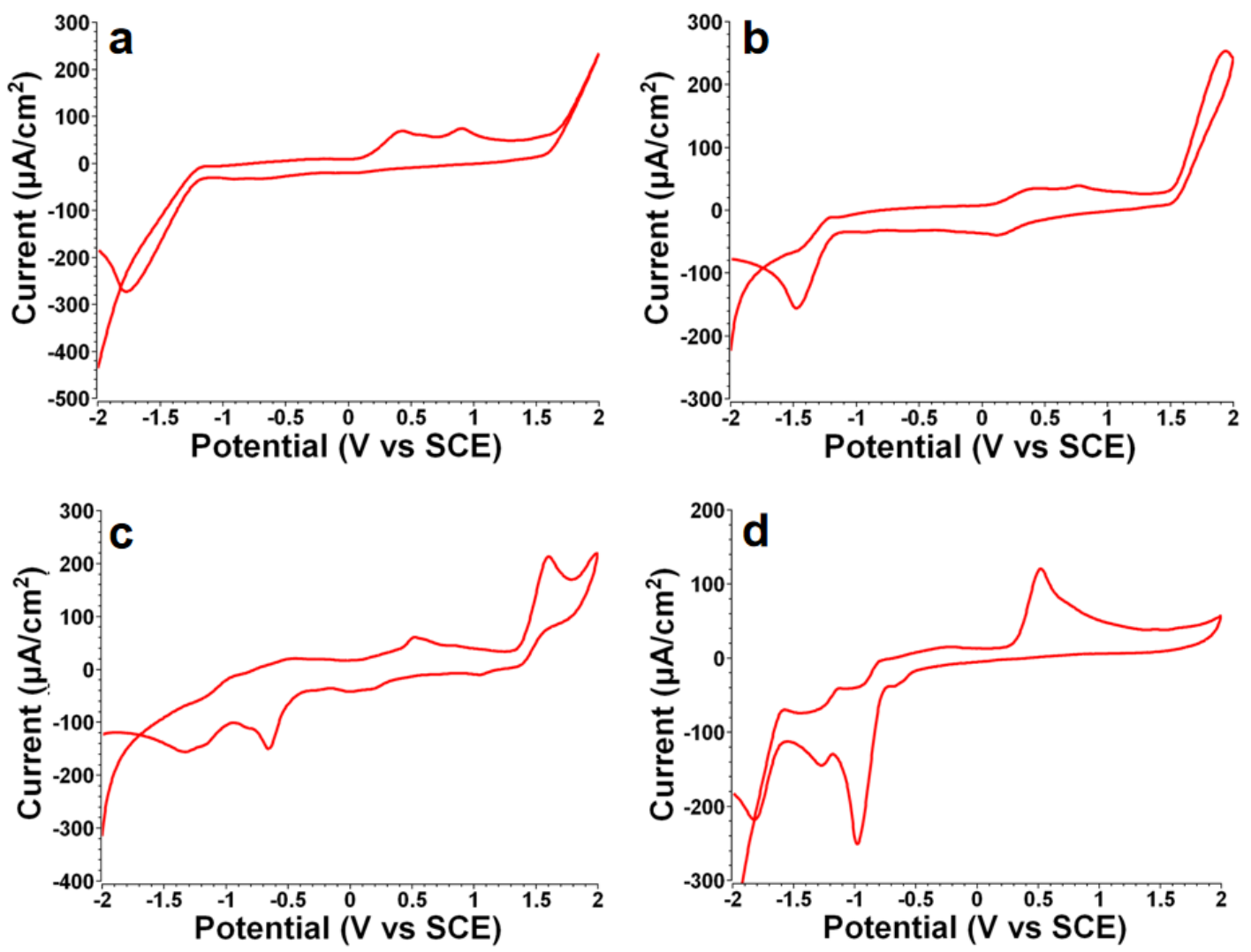

Figure 6. Cyclic voltammograms of dyes 1, 3, 5, 6 recorded in acetonitrile against saturated calomel electrode (SCE) under nitrogen saturated solution: (a) dye 1; (b) dye $3 ;$ (c) dye 5; (d) dye 6.

Table 3. Parameters characterizing the chemical mechanisms associated with dyes 1, 3, 5,6 in acetonitrile. ${ }^{a, b}$

\begin{tabular}{|c|c|c|c|c|}
\hline & Dye 1 & Dye 3 & Dye 5 & Dye 6 \\
\hline $\mathbf{E}_{\mathbf{S 1}}(\mathbf{e V})$ & 3.07 & 2.96 & 2.39 & 2.17 \\
\hline $\mathbf{E}_{\mathbf{T 1}}(\mathbf{e V})^{\mathbf{a}}$ & 2.12 & 2.10 & 1.31 & 2.05 \\
\hline$\Delta \mathbf{G}_{\text {Iod }}^{\mathbf{S}}(\mathbf{e V})$ & -2.09 & -2.02 & -1.22 & -1.05 \\
\hline
\end{tabular}




\begin{tabular}{|c|c|c|c|c|}
\hline$\Delta \mathbf{G}^{\mathrm{S1}}{ }_{\mathbf{E D B}}(\mathbf{e V})$ & $>-0.07$ & -0.64 & -0.82 & -0.31 \\
\hline$\Delta \mathbf{G e t}^{\mathrm{T1}}{ }_{\text {Iod }}(\mathbf{e V})$ & -1.14 & -1.16 & -0.14 & -0.93 \\
\hline$\Delta \mathbf{G e t}^{\mathrm{T1}}{ }_{\mathrm{EDB}}(\mathbf{e V})$ & $>0.88$ & 0.22 & 0.26 & -0.19 \\
\hline $\mathbf{E}_{\text {ox }}(\mathbf{e V})$ & 0.28 & 0.24 & 0.47 & 0.42 \\
\hline $\mathbf{E}_{\text {red }}(\mathbf{e V})$ & $<-2.00$ & -1.32 & -0.57 & -0.86 \\
\hline
\end{tabular}

a: For Iod, the reduction potential of $-0.7 \mathrm{~V}$ is used according to ref. [39].

b: calculated triplet state energy level at DFT level.

The involved chemical mechanisms during the polymerization processes were also investigated using fluorescence quenching experiments on dye 5 and dye 6 in acetonitrile (see Figure 7). Precisely, parameters such as the Stern-Volmer coefficients (Ksv) and the electron transfer quantum yields $\left(\phi_{\mathrm{et}}\right)$ were determined from the fluorescence quenching experiments. This is a useful method to evaluate the efficiency of the dye/Iod and dye/EDB interactions. These parameters are presented in Table 4. A decline process was found for the fluorescence quenching of dye 5/EDB and dye 6/Iod solutions (see Figure 7 a for dye 5/EDB, Figure 7c for dye 6/Iod). Thus, linear quenching processes could be established using the Stern-Volmer treatment for fluorescence quenching as showed in Figure $7 \mathrm{~b}$ for dye 5/EDB and Figure $7 \mathrm{~d}$ for dye 6/Iod. Moreover, the slope of Stern-Volmer treatment also determine the Stern-Volmer coefficients Ksv and the electron transfer quantum yields $\left(\phi_{\mathrm{et}}\right)$, which were calculated from eq2. However, for the other combinations e.g. dye 5/Iod, dye 6/EDB, dye 1/Iod (or EDB) and dye 3/Iod (or EDB), no fluorescence quenching processes were observed, indicating poor interactions existing in these two-component systems. Remarkably, even if the free energy changes of dye 5/Iod and dye 6/EDB combinations are less than $0\left(\Delta \mathrm{G}_{\text {Iod }}=-1.22 \mathrm{eV}\right.$ for dye; $\Delta \mathrm{G}_{\mathrm{EDB}}=-0.314 \mathrm{eV}$ for dye 6$)$ as mentioned above, the poor interactions within dye 5/Iod and dye 6/EDB confirmed by fluorescence quenching 
approaches are in full agreement with the results attained by steady state photolysis, for which only slight declines were observed during the photolysis processes.
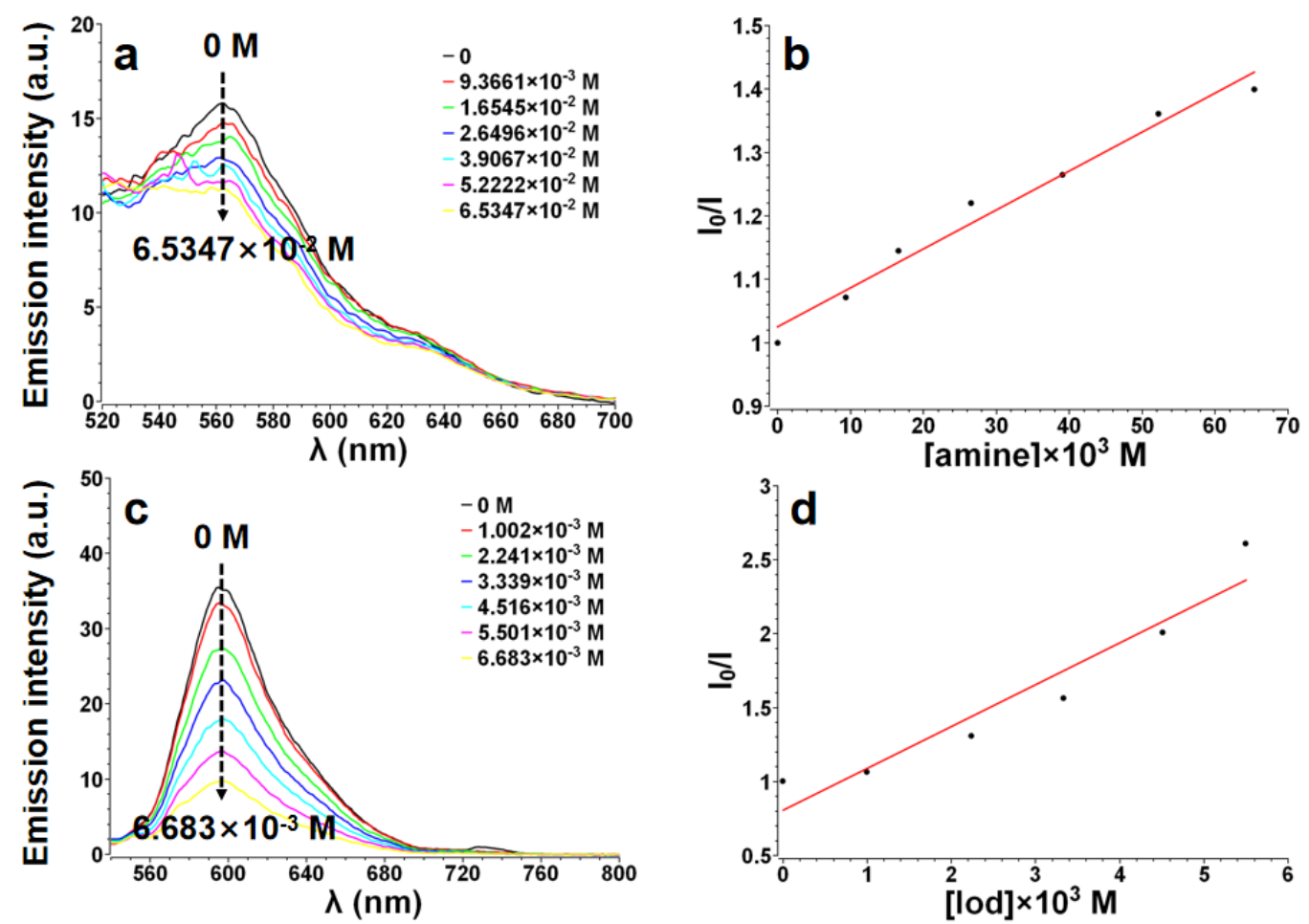

Figure 7. Fluorescence quenching of: (a) dye $5\left(1.23 \times 10^{-5} \mathrm{M}\right.$ in acetonitrile) by the amine (EDB); (c) dye $6\left(1.48 \times 10^{-5} \mathrm{M}\right.$ in acetonitrile) by iodonium salt (Iod). Stern-Volmer treatment for fluorescence quenching of the (b) dye 5/EDB; (d) dye 6/Iod.

Table 4. Parameters characterizing the fluorescence properties of dyes 5, 6 in acetonitrile: Interaction constant (Ksv) between dye/Iod and dye/EDB systems calculated by Stern-Volmer equation; electron transfer quantum yield $\left(\phi_{\mathrm{et}(\mathrm{S} 1)}\right)$ of 
dye/Iod and dye/EDB interaction.

\begin{tabular}{|c|c|c|c|c|}
\hline & $\mathbf{K}_{\text {Iod }}^{\mathrm{sv}}\left(\mathbf{M}^{-1}\right)$ & $\phi^{\mathrm{et}(\mathrm{S} 1)} \operatorname{Iod}^{\mathrm{a}}$ & $\mathbf{K}^{\mathrm{sv}}{ }_{\text {EDB }}\left(\mathbf{M}^{-1}\right)$ & $\phi^{\mathrm{et}(\mathrm{S} 1)} \mathbf{E D B}^{\mathrm{a}}$ \\
\hline Dye 5 & - & - & 6.13 & 0.42 \\
\hline Dye 6 & 383 & 0.94 & - & - \\
\hline
\end{tabular}

\subsubsection{ESR spin-trapping experiments}

In this part, a clear chemical interaction between the dyes and Iod or EDB upon excitation at $405 \mathrm{~nm}$ has also been observed during the ESR-spin trapping experiments. The $\mathrm{Ar}^{\bullet}$ and $\mathrm{EDB}^{\bullet}(-\mathrm{H})$ radicals formed from Iod and EDB in presence of dye during the irradiation with the LED could be detected in the different solutions, as a confirmation of the proposed chemical mechanism mentioned above. ${ }^{45}$ The solutions constituted by a mixture of the selected dyes (dyes 1, 3, 6) and the Iodonium salt (or EDB) in tert-butylbenzene at weight concentration ratio ([dye] $=0.2 \mathrm{mg} / \mathrm{mL} ;\left[\right.$ Iod] $=2 \mathrm{mg} / \mathrm{mL} ;[\mathrm{EDB}]=2 \mathrm{mg} / \mathrm{mL}$ ) under protection gas, $\mathrm{N}_{2}$, then the spin trap agent, PBN $(2 \mathrm{mg} / \mathrm{mL})$, was also dissolved into the solution. The experimental results and ESR spectra of dyes with Iod (or EDB) both before and after irradiation at $405 \mathrm{~nm}$ are presented in Figure 8 for dye 6, Figure $\mathrm{S} 3$ for dye 1 and Figure S4 for dye 3. Particularly, the ESR spectra for the dye 6/Iod and dye 6/EDB combinations under sunlight were also acquired and the spectra are presented in Figure 9. When compared to the ESR spectra obtained upon LED irradiation, enhancement of the ESR curves under sunlight were also obvious even if they were taken after higher irradiation time i.e. $15 \mathrm{~min}$. Interestingly, the free radical polymerization can also be initiated by the mild weather conditions without sunlight: rainy, grey clouds (see polymerization data above). The ESR-spin experiments were performed around 3:00 pm on $3^{\text {rd }}$, Nov. 2020, in Mulhouse Area $\left(+77^{\circ}\right.$ 
$43^{\prime} \mathrm{E},-47^{\circ} 75^{\prime} \mathrm{N}$ ) of France, and the weather conditions are illustrated in Figure S5.

Hyperfine Couplings Constants (HFCs) for the PBN radical adducts were simulated by ESR spectra and the results are gathered in Table 5. The results are consistent to the literature data. ${ }^{46,47}$
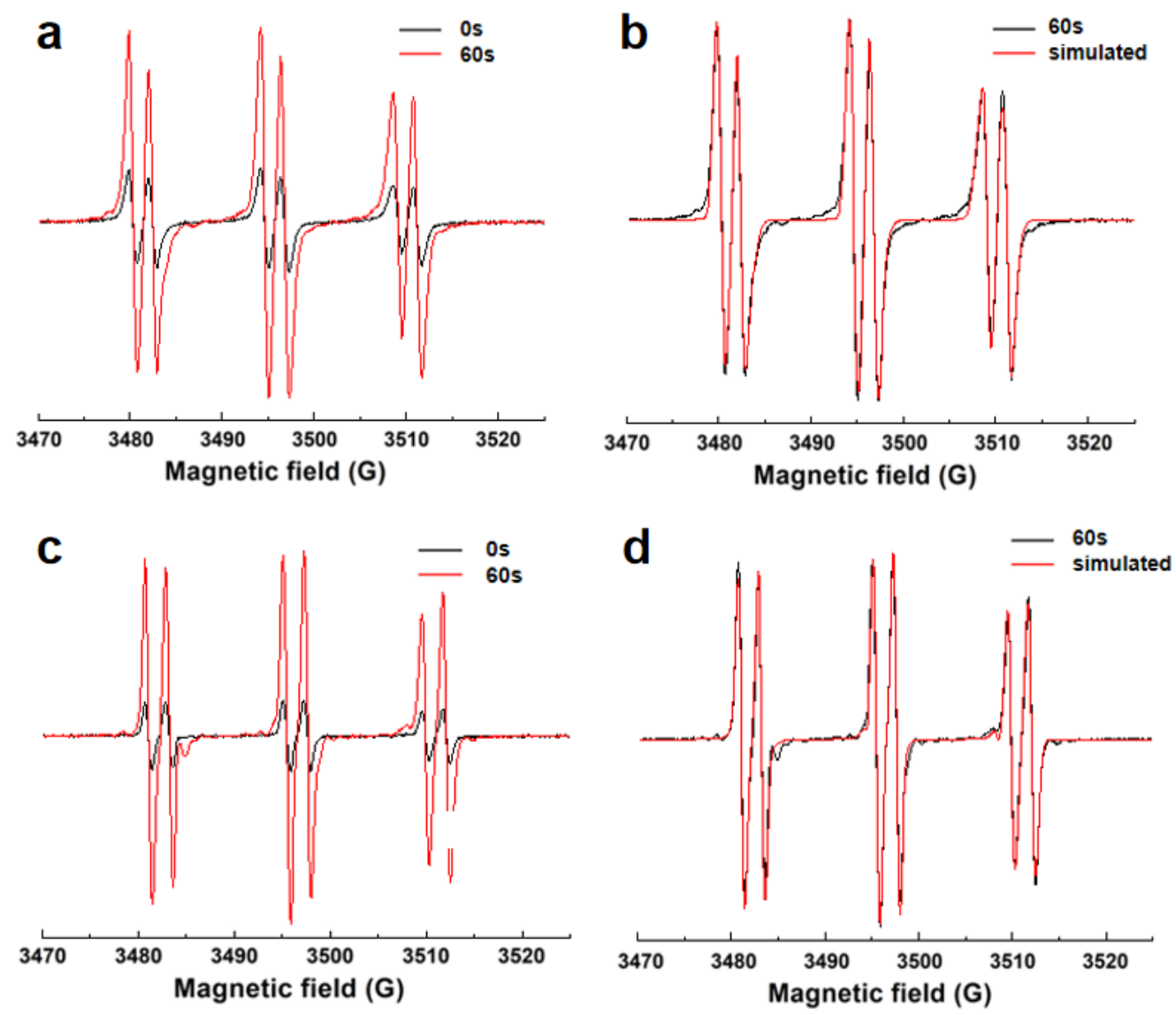

Figure 8. ESR spectra obtained from ESR-spin trapping experiments under irradiation of $405 \mathrm{~nm}$ LED using PBN $=2 \mathrm{mg} / \mathrm{mL}$ (as the spin trap agent); Iod $=2 \mathrm{mg} / \mathrm{mL}$, EDB $=2 \mathrm{mg} / \mathrm{mL}$ and dye $6=0.2 \mathrm{mg} / \mathrm{mL}$ in tert-butylbenzene under $\mathrm{N}_{2}$. (a) dye $6 / \mathbf{I o d}$ PIS, Irradiation time $=60 \mathrm{~s}$ (red) and $=0 \mathrm{~s}$ (black) spectra, respectively; (b) dye 6/Iod PIS, Irradiation time $=60 \mathrm{~s}$ experimental (black) and simulated (red) spectra; (c) dye 6/EDB PIS, Irradiation time $=60 \mathrm{~s}$ (red) and $=0 \mathrm{~s}$ (black) spectra; (d) dye 6/EDB PIS, Irradiation time $=60$ s experimental (black) and simulated (red) spectra. 

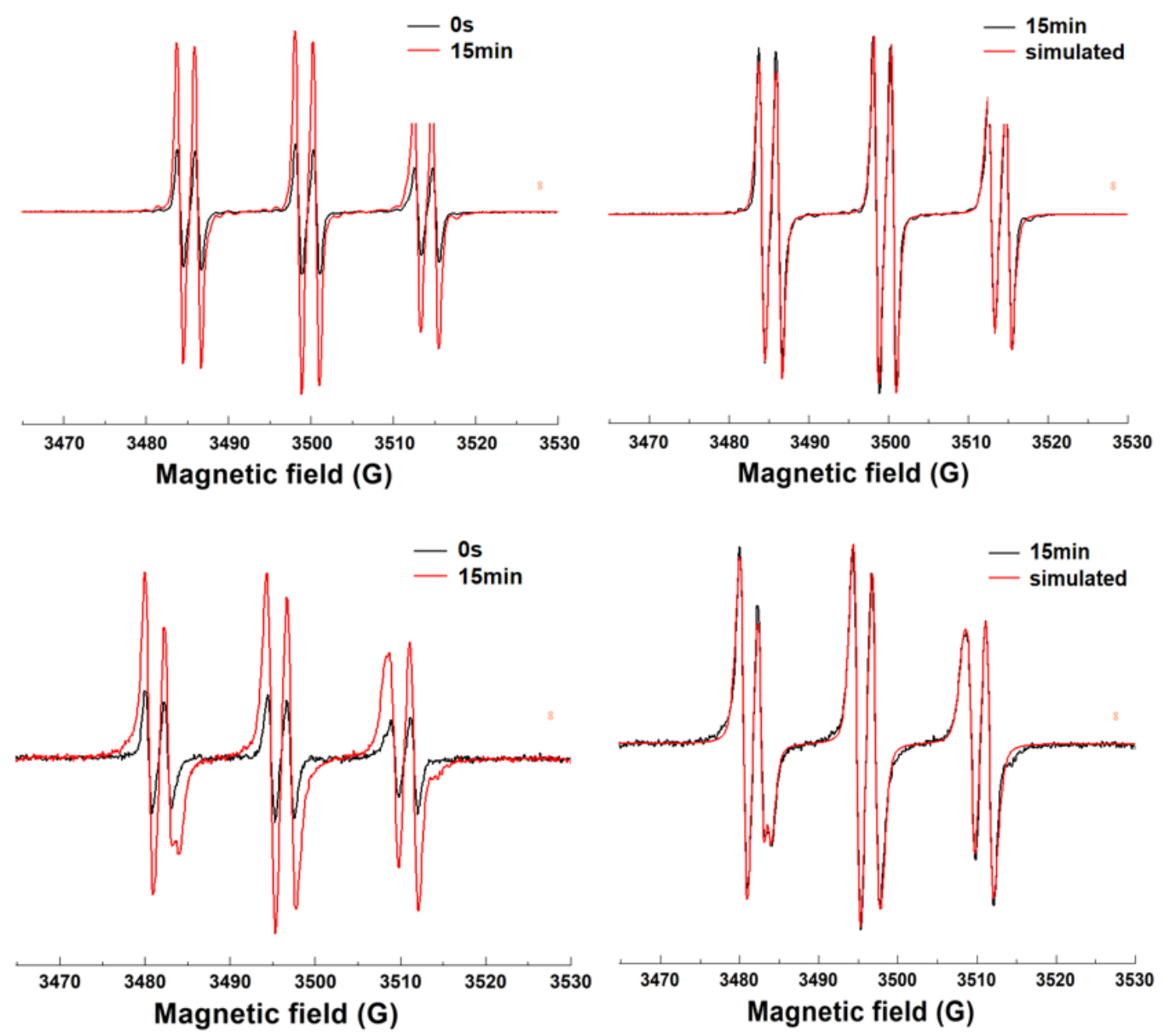

Figure 9. ESR spectra obtained from ESR-spin trapping experiments under irradiation of sunlight using PBN $=2 \mathrm{mg} / \mathrm{mL}$ (as the spin trap agent); Iod $=2 \mathrm{mg} / \mathrm{mL}, \mathrm{EDB}=2$ $\mathrm{mg} / \mathrm{mL}$ and dye $6=0.2 \mathrm{mg} / \mathrm{mL}$ in tert-butylbenzene under $\mathrm{N}_{2}$. (a) dye 6/Iod PIS, Irradiation time $=15 \mathrm{~min}$ (red) and $=0 \mathrm{~min}$ (black) spectra, respectively; (b) dye 6/Iod PIS, Irradiation time $=15$ min experimental (black) and simulated (red) spectra; (c) dye 6/EDB PIS, Irradiation time $=15 \mathrm{~min}$ (red) and $=0 \mathrm{~min}$ (black) spectra; (d) dye 6/EDB PIS, Irradiation time $=15$ min experimental (black) and simulated (red) spectra.

Table 5. HFC constants determined by ESR-spin experiments for the dyes 1, 3, 6 (sunlight included).

\begin{tabular}{|c|c|c|c|c|}
\hline & Dye 1 & Dye 3 & $\begin{array}{c}\text { Dye 6 at } \\
405 \mathrm{~nm} \text { LED }\end{array}$ & $\begin{array}{c}\text { Dye 6 at } \\
\text { sunlight }\end{array}$ \\
\hline Iod & $\mathrm{a}_{\mathrm{N}}=14.4$ & $\mathrm{a}_{\mathrm{N}}=14.4$ & $\mathrm{a}_{\mathrm{N}}=14.3$ & $\mathrm{a}_{\mathrm{N}}=14.4$ \\
\hline
\end{tabular}




\begin{tabular}{|c|c|c|c|c|}
\hline & $\mathrm{a}_{\mathrm{H}}=2.1$ & $\mathrm{a}_{\mathrm{H}}=2.2$ & $\mathrm{a}_{\mathrm{H}}=2.2$ & $\mathrm{a}_{\mathrm{H}}=2.2$ \\
\hline \multirow{2}{*}{ EDB } & $\mathrm{a}_{\mathrm{N}}=14.4$ & $\mathrm{a}_{\mathrm{N}}=14.4$ & $\mathrm{a}_{\mathrm{N}}=14.4$ & $\mathrm{a}_{\mathrm{N}}=14.4$ \\
& $\mathrm{a}_{\mathrm{H}}=2.1$ & $\mathrm{a}_{\mathrm{H}}=2.2$ & $\mathrm{a}_{\mathrm{H}}=2.2$ & $\mathrm{a}_{\mathrm{H}}=2.2$ \\
\hline
\end{tabular}

\subsection{Direct laser writing (DLW) experiments}

According to the polymerization behaviors of TA in the presence of the different dyes (see above), DLW experiments were carried out to evidence the potential applications of our three-component systems in practical applications with a selected set of push-pull dyes (dyes 5,6) due to their excellent photoinitiation abilities. Indeed, the three-component systems comprising dyes $5,6 / \operatorname{Iod} / \operatorname{EDB}(0.1 \% / 2 \% / 2 \%$ in monomer, $\mathrm{w} / \mathrm{w} / \mathrm{w})$ used in this part are the same than the compositions and concentrations used before. Moreover, the tridimensional patterns with smooth surfaces and excellent spatial resolution were also successfully fabricated via DLW experiments in a very short time, and profilometric observations on these 3D profiles were performed by numerical optical microscopy (“SRZ” for dyes 5, 6, see Figure 10a, b).

Photocomposites prepared with the selected PISs were also produced and examined by DLW experiments and numerical optical microscopy, respectively. Here, silica powers act as fillers added into the monomer (TA) with a weight ratio of $20 \%$. Markedly, 3D profiles of solidified photocomposites with an excellent spatial resolution were attained under initiation with dyes 5 and 6-based PISs ("SRZ” for dye 5/silica, dye 6/silica, see Figures 10c, d, respectively). As a result, the success of this kind of photocomposite proved the remarkable photoinitiation abilities of selected push-pull dyes even if in the presence of silica fillers and can be regarded as useful photopolymerizable materials in the potential field of additive manufacturing/vat photopolymerization. 

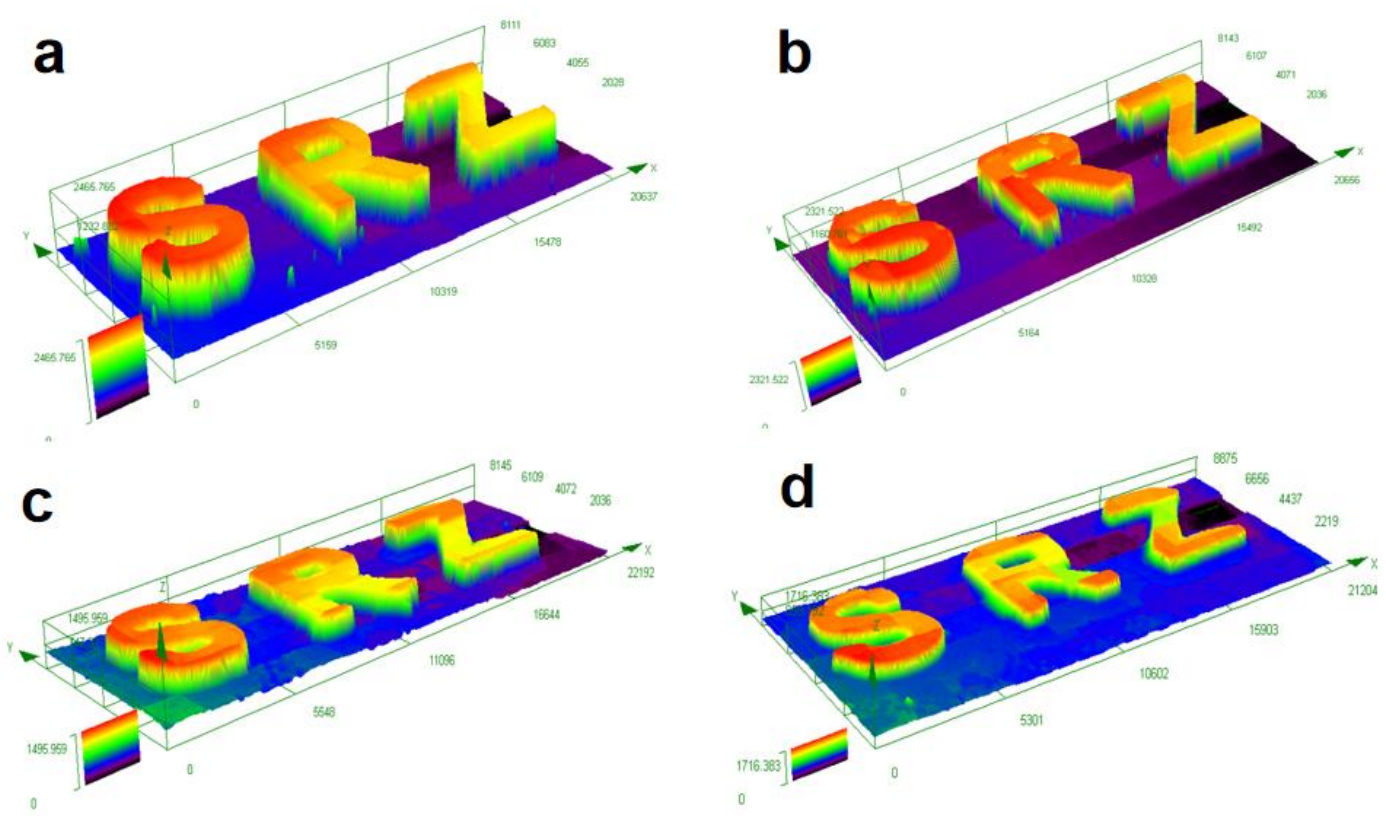

Figure 10. Free radical photopolymerization experiments in DLW experiments in TA. Characterization of 3D overall appearance of color patterns by numerical optical microscopy in the presence of: (a) dye $5 / \operatorname{Iod} / \operatorname{EDB}(0.1 \% / 2 \% / 2 \%$ in TA, w/w/w); (b) dye $6 / \mathrm{Iod} / \mathrm{EDB} /$ silica $(0.1 \% / 2 \% / 2 \%$ in TA, w/w/w); (c) dye $5 / \mathrm{Iod} / \mathrm{EDB} / \mathrm{silica}$ $(0.1 \% / 2 \% / 2 \% / 20 \%$ in TA, w/w/w/w); (d) dye $6 / \mathrm{Iod} / \mathrm{EDB} /$ silica $(0.1 \% / 2 \% / 2 \% / 20 \%$ in $\mathrm{TA}, \mathrm{w} / \mathrm{w} / \mathrm{w} / \mathrm{w})$;

\section{Conclusion}

In this article, 6 novel dyes based on push-pull structures with high light absorption properties were synthesized. Their performances in free radical polymerization were examined under the irradiation of the LED@405 nm. Furthermore, four dyes were selected for their good performances (short induction time or high final conversion) at $405 \mathrm{~nm}$, and the abilities to initiate the polymerization process with sunlight were also examined. The results indicated that the photoinitiation abilities of the different dyebased PISs were remarkable since polymerization processes could be efficiently initiated upon sunlight irradiation. Their reactivities were investigated by UV-visible absorption and fluorescence approaches. Feasibility of the proposed photochemical mechanism was also discussed and confirmed by the ESR experiments. With aim at 
broaden the polymerizable materials in photochemistry, DLW experiments were performed on the monomer containing the selected dyes-based photoinitiating systems. As expected, 3D patterns were successfully prepared, even if in the case of the photocomposite in the presence of silica fillers, indicating the related potential applications in material chemistry.

Supplementary Materials: Figure S1. UV-visible absorption spectra of dyes 1 and 3; Figure S2. Singlet state energy determination in acetonitrile for dye 1, 3, 5 and 6; Figure S3. ESR spectra of dye 1 obtained from ESR-spin trapping experiment at 405nm LED; Figure S4. ESR spectra of dye 3 obtained from ESR-spin trapping experiment at 405nm LED; Figure S5. The Shortcuts of weather and address of experiments performed for sunlight irradiation.

Funding: China Scholarship Council (CSC) for Ke Sun.

Acknowledgments: This research project is supported by China Scholarship Council (CSC) (No.201808440451). PX acknowledges funding from the "Australian Research Council (FT170100301)". This work was granted access to the HPC resources of the Mesocentre of the University of Strasbourg.

Conflicts of Interest: The authors declare no conflict of interest. 


\section{References}

(1) Noirbent, G.; Dumur, F. Recent advances on nitrofluorene derivatives: Versatile electron acceptors to create dyes absorbing from the visible to the near and far-infrared region. Materials 2018, 11(12), 2425.

(2) Blanchard-Desce, M.; Wortmann, R.; Lebus, S.; Lehn, J. M.; Krämer, P. Intramolecular charge transfer in elongated donor-acceptor conjugated polyenes. Chem. Phys. Lett. 1995, 243(5-6), 526-532.

(3) Noirbent, G.; Pigot, C.; Bui, T.-T.; Péralta, S.; Nechab, M.; Gigmes, D.; Dumur, F. Synthesis, optical and electrochemical properties of a series of push-pull dyes based on the 2-(3-cyano-4,5,5-trimethylfuran-2(5H)-ylidene) malononitrile (TCF) acceptor, Dyes and Pigments 2021, 184, 108807.

(4) Pigot, C.; Noirbent, G.; Peralta, S.; Duval, S.; Nechab, M.; Gigmes, D.; Dumur, F. Unprecedented Nucleophilic Attack of Piperidine on the Electron Acceptor during the Synthesis of Push-Pull Dyes by a Knoevenagel Reaction. Helv. Chim. Acta 2019, 102, e1900229.

(5) Bureš, F. Fundamental aspects of property tuning in push-pull molecules. Rsc Advances 2014, 4(102), 58826-58851.

(6) Tehfe, M. A.; Dumur, F.; Graff, B.; Morlet-Savary, F.; Fouassier, J. P.; Gigmes, D.; Lalevée, J. New Push-Pull Dyes Derived from Michler's Ketone For Polymerization Reactions Upon Visible Lights. Macromolecules 2013, 46(10), 37613770.

(7) Tehfe, M. A.; Dumur, F.; Graff, B.; Morlet-Savary, F.; Gigmes, D.; Fouassier, J. P.; Lalevée, J. Push-pull (thio) barbituric acid derivatives in dye photosensitized radical and cationic polymerization reactions under $457 / 473 \mathrm{~nm}$ laser beams or blue LEDs. Polymer Chemistry 2013, 4(13), 3866-3875. 
(8) Tehfe M. A.; Dumur, F.; Graff, B.; Morlet-Savary, F.; Gigmes, D.; Fouassier, J. P.; Lalevée, J. New push-pull dyes derived from Michler's ketone for polymerization reactions upon visible lights. Macromolecules 2013, 46(10), 3761-3770.

(9) Xiao, P.; Frigoli, M.; Dumur, F.; Graff, B.; Gigmes, D.; Fouassier, J. P.; Lalevée, J. Julolidine or fluorenone based push-pull dyes for polymerization upon soft polychromatic visible light or green light. Macromolecules 2014, 47(1), 106-112.

(10) Sun, K.; Pigot, C.; Chen, H.; Nechab, M.; Gigmes, D.; Morlet-Savary, F.; Graff, B.; Liu, S. Xiao, P.; Dumur, F.; Lalevée, J. Free radical photopolymerization and 3d printing using newly developed dyes: Indane-1, 3-dione and $1 \mathrm{H}$ cyclopentanaphthalene-1, 3-dione derivatives as photoinitiators in three-component systems. Catalysts 2020, 10(4), 463.

(11) Paek, S.; Lee, J.K.; Ko, J. Synthesis and photovoltaic characteristics of pushpull organic semiconductors containing an electron-rich dithienosilole bridge for solution-processed small-molecule organic solar cells. Sol. Energ. Mater. Solar Cells 2014, 120, 209-217.

(12) Xu, S. J.; Zhou, Z.; Liu, W.; Zhang, Z.; Liu, F.; Yan, H.; Zhu, X. A twisted thieno[3,4- $b]$ thiophene-based electron acceptor featuring a 14- $\pi$-electron indenoindene core for high-performance organic photovoltaics. Adv. Mater. 2017, 29(43), 1704510.

(13) Turkoglu, G.; Cinar, M.E.; Ozturk, T. Triarylborane-based materials for OLED applications. Molecules 2017, 22(9), 1522.

(14) Karak, S.; Liu, F.; Russell, T.P.; Duzhko, V.V. Bulk charge carrier transport in push-pull type organic semiconductor. ACS Appl. Mater. Interfaces 2014, 6(23), 20904-20912.

(15) Raimundo, J.M.; Blanchard, P.; Gallego-Planas, N.; Mercier, N.; Ledoux-Rak, I.; Hierle, R.; Roncali, J. Design and synthesis of push-pull chromophores for second- 
order nonlinear optics derived from rigidified thiophene-based $\pi$-conjugating spacers. J. Org. Chem. 2002, 67(1), 205-218.

(16) El-Shishtawy, R.M.; Borbone, F.; Al-amshany, Z.M.; Tuzi, A.; Barsella, A.; Asiri, A.M.; Roviello, A. Thiazole azo dyes with lateral donor branch: Synthesis, structure and second order NLO properties. Dyes Pigments. 2013, 96(1), 45-51.

(17) Cesaretti, A.; Bonaccorso, C.; Elisei, F.; Fortuna, C. G.; Mencaroni, L.; Spalletti, A. Photoinduced Intramolecular Charge Transfer and Hyperpolarizability Coefficient in Push-Pull Pyridinium Salts with Increasing Strength of the Acceptor Group. ChemPlusChem 2018, 83(11), 1021-1031.

(18) Motiei, H.; Jafari, A.; Naderali, R. Third-order nonlinear optical properties of organic azo dyes by using strength of nonlinearity parameter and Z-scan technique. Optics \& Laser Technology 2017, 88, 68-74.

(19) El-Shishtawy, R. M.; Al-Zahrani, F. A.; Afzal, S. M.; Razvi, M. A. N.; Alamshany, Z. M.; Bakry, A. H.; Asiri, A. M. Synthesis, linear and nonlinear optical properties of a new dimethine cyanine dye derived from phenothiazine. RSC advances 2016, 6(94), 91546-91556.

(20) Gao, S. H.; Xie, M. S.; Wang, H. X.; Niu, H. Y.; Qu, G. R.; Guo, H. M. Highly selective detection of $\mathrm{Hg} 2+$ ion by push-pull-type purine nucleoside-based flfluorescent sensor. Tetrahedron 2014, 70(33), 4929- 4933.

(21) Sun, K.; Liu, S.; Pigot, C.; Brunel, D.; Graff, B.; Nechab, M.; ... \& Dumur, F. Novel Push-Pull Dyes Derived from 1H-cyclopenta [b] naphthalene-1, 3 (2H)-dione as Versatile Photoinitiators for Photopolymerization and Their Related Applications: 3D Printing and Fabrication of Photocomposites. Catalysts 2020, 10(10), 1196.

(22) Xiao P.; Frigoli M.; Dumur F.; Graff B.; Gigmes D.; Fouassier JP.; Lalevée J. Julolidine or Fluorenone Based Push-Pull Dyes for Polymerization upon Soft Polychromatic Visible Light or Green Light. Macromolecules. 2014, 47(1):106-112.

(23) Allegrezza, M. L.; DeMartini, Z. M.; Kloster, A. J.; Digby, Z. A.; Konkolewicz, 
D. Visible and sunlight driven RAFT photopolymerization accelerated by amines: kinetics and mechanism. Polymer Chemistry 2016, 7(43), 6626-6636.

(24) Wang, J.; Rivero, M.; Muñoz Bonilla, A.; Sanchez-Marcos, J.; Xue, W.; Chen, G.; Zhang, W; Zhu, X. Natural RAFT polymerization: recyclable-catalyst-aided, opened-to-Air, and sunlight-photolyzed RAFT polymerizations. ACS Macro Letters 2016, 5(11), 1278-1282.

(25) Ciftci, M.; Tasdelen, M. A.; Yagci, Y. Sunlight induced atom transfer radical polymerization by using dimanganese decacarbonyl. Polymer Chemistry 2014, 5(2), 600-606.

(26) Decker, C.; Bendaikha, T. Interpenetrating polymer networks. II. Sunlightinduced polymerization of multifunctional acrylates. Journal of applied polymer science 1998, 70(11), 2269-2282.

(27) Fouassier, J. P.; Allonas, X.; Burget, D. Photopolymerization reactions under visible lights: principle, mechanisms and examples of applications. Progress in organic coatings 2003, 47(1), 16-36.

(28) Schmitt, M. Synthesis and testing of $\mathrm{ZnO}$ nanoparticles for photo-initiation: experimental observation of two different non-migration initiators for bulk polymerization. Nanoscale 2015, 7(21), 9532-9544.

(29) Sun, K.; Liu, S.; Chen, H.; Morlet-Savary, F.; Graff, B.; Pigot, C.; Nechab, M.; Xiao, P.; Dumur, F.; Lalevée, J. N-ethyl Carbazole-1-Allylidene-Based Push-Pull Dyes as Efficient Light Harvesting Photoinitiators for Sunlight Induced Polymerization. European Polymer Journal 2021, 147, 110331.

(30) Decker, C.; Bendaikha, T. Interpenetrating polymer networks. II. Sunlightinduced polymerization of multifunctional acrylates. Journal of applied polymer science 1998, 70(11), 2269-2282.

(31) Ciftci, M.; Tasdelen, M. A.; Yagci, Y. Sunlight induced atom transfer radical 
polymerization by using dimanganese decacarbonyl. Polymer Chemistry 2014, 5(2), 600-606.

(32) Tehfe, M. A.; Lalevée, J.; Gigmes, D.; Fouassier, J. P. Green chemistry: sunlight-induced cationic polymerization of renewable epoxy monomers under air. Macromolecules 2010, 43(3), 1364-1370.

(33) Tehfe, M. A.; Lalevée, J.; Morlet-Savary, F.; Graff, B.; Fouassier, J. P. A breakthrough toward long wavelength cationic photopolymerization: Initiating systems based on violanthrone derivatives and silyl radicals. Macromolecules 2011, 44(21), 8374-8379.

(34) Dietlin, C.; Schweizer, S.; Xiao, P.; Zhang, J.; Morlet-savary, F.; Graff, B.; Fouassier, J. P.; Lalevée, J. Photopolymerization upon LEDs: new photoinitiating systems and strategies. Polym. Chem. 2015, 6(21), 3895-3912.

(35) Lalevée, J.; Blanchard, N.; Tehfe, M.A.; Morlet-Savary, F.; Fouassier, J. P. Green bulb light source induced epoxy cationic polymerization under air using tris (2, 2'-bipyridine) ruthenium (II) and silyl radicals. Macromolecules 2010, 43(24), 1019110195.

(36) Lalevée, J.; Blanchard, N.; Tehfe, M.A.; Peter, M.; Morlet- Savary, F.; Gigmes, D.; Fouassier, J. P. Efficient dual radical/cationic photoinitiator under visible light: a new concept. Polym. Chem., 2011, 2(9), 1986-1991.

(37) Xu, Y. Y.; Ding, Z. F.; Liu, F. Y.; Sun, K.; Dietlin, C.; Lalevée, J.; Xiao, P. 3D Printing of Polydiacetylene Photocomposite Materials: Two Wavelengths for Two Orthogonal Chemistries. ACS Applied Materials \& Interfaces 2019, 12(1), 1658-1664.

(38) Rehm, D.; Weller, A. Kinetics of fluorescence quenching by electron and Hatom transfer. Isr. J. Chem. 1970, 8(2), 259-271.

(39) Romanczyk, P. P.; Kurek, S. S. The Reduction Potential of Diphenyliodonium Polymerisation Photoinitiator Is Not -0.2 V vs. SCE. A Computational Study Electrochim. Acta 2017, 225, 482-485. 
(40) Fouassier, J. P.; Lalevée, J. Photoinitiators for polymer synthesis - scope, reactivity, and efficiency. Weinheim: John Wiley \& Sons, 2012.

(41) James, B.; Frisch, A. Exploring chemistry with electronic structure methods. Gaussian, Incorporated, 1996.

(42) Frisch, M. J.; Trucks, G. W.; Schlegel, H. B.; Scuseria, G. E.; Robb, M. A.; Cheeseman, J. R.; Zakrzewski, V. G.; Montgomery, J. A.; Stratmann, R. E.; Burant, J. C.; Dapprich, S.; Millam, J. M.; Daniels, A. D.; Kudin, K. N.; Strain, M. C.; Farkas, O.; Tomasi, J.; Barone, V.; Cossi, M.; Cammi, R.; Mennucci, B.; Pomelli, C.; Adamo, C.; Clifford, S. J.; Ochterski, W.; Petersson, G. A.; Ayala, P. Y.; Cui, Q.; Morokuma, K.; Salvador, P.; Dannenberg, J. J.; Malick, D. K.; Rabuck, A. D.; Raghavachari, K.; Foresman, J. B.; Cioslowski, J.; Ortiz, J. V.; Baboul, A. G.; Stefanov, B. B.; Liu, G.; Liashenko, A.; Piskorz, P.; Komaromi, I.; Gomperts, R.; Martin, R. L.; Fox, D. J.; Keith, T.; Al-Laham, M. A.; Peng, C. Y.; Nanayakkara, A.; Challacombe, M.; Gill, P. M. W.; Johnson, B.; Chen, W.; Wong, M. W.; Andres, J. L.; Gonzalez, C.; Head-Gordon, M.; Replogle, E. S.; Pople, J. A. Gaussian 03, Revision B-2, Gaussian Inc., Pittsburgh, PA, 2003.

(43) Garra, P.; Graff, B.; Morlet-Savary, F.; Dietlin, C.; Becht, J. M.; Fouassier, J. P.; Lalevée, J. Charge transfer complexes as pan-scaled photoinitiating systems: from 50 $\mu \mathrm{m} 3 \mathrm{D}$ printed polymers at $405 \mathrm{~nm}$ to extremely deep photopolymerization (31 cm). Macromolecules 2018, 51(1), 57-70.

(44) Noirbent, G.; Dumur, F. Recent Advances on Copper Complexes as Visible Light Photoinitiators and (Photo) Redox Initiators of Polymerization. Catalysts 2020, $10(9), 953$.

(45) Sun, K.; Xu, Y.; Dumur, F.; Morlet-Savary, F.; Chen, H.; Dietlin, C.; Graff, B.; Lalevée, J.; Xiao, P. In silico rational design by molecular modeling of new ketones as photoinitiators in three-component photoinitiating systems: application in 3D printing. Polymer Chemistry 2020, 11(12), 2230-2242. 
(46) Haire, L.D.; Krygsman, P.H.; Janzen, E.G.; Oehler, U.M. Correlation of radical structure with EPR spin adduct parameters: utility of the proton, carbon-13, and nitrogen-14 hyperfine splitting constants of aminoxyl adducts of $\mathrm{PBN}$-nitronyl- ${ }^{13} \mathrm{C}$ for three-parameter scatter plots. J. Org. Chem. 1988, 53, 4535-4542.

(47) Ohto, N.; Niki, E.; Kamiya, Y. Study of autoxidation by spin trapping. Spin trapping of peroxyl radicals by phenyl N-t-butyl nitrone. J. Chem. Soc., Perkin Trans. $2,1977,13,1770-1774$ 


\section{TOC graphic:}

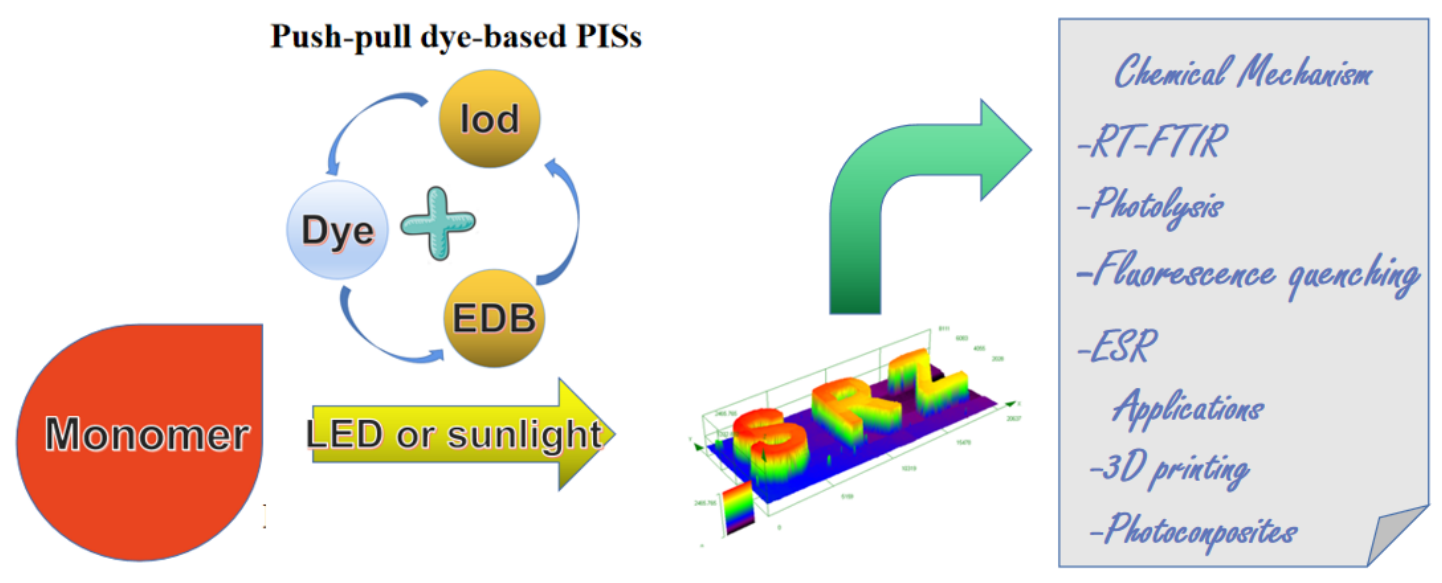

Free radical polymerization 